\title{
NOVAS LINHAS DE POBREZA PARA O BRASIL: UMA ANÁLISE A PARTIR DAS PESQUISAS DE ORÇAMENTOS FAMILIARES (POF) 2002-2003 E 2008-2009
}

\author{
Cristiana Tristão Rodrigues * \\ Steven M. Helfand ${ }^{\dagger}$ \\ JoÃo EUSTÁQUio DE LIMA $\ddagger$
}

\begin{abstract}
Resumo
O objetivo deste artigo é obter novas linhas de pobreza para o Brasil baseado nos dados das Pesquisas de Orçamentos Familiares 2002-2003 e 2008-2009. Uma metodologia de imputações para erros de mensuração e para fluxo de serviços com bens duráveis é apresentada. São estimadas linhas de pobreza de alimentos e linhas ajustadas para itens não alimentares. Embora apenas 2,1\% e 10,7\% da população tenham sido considerados extremamente pobres e pobres com base nas linhas do Programa Bolsa Família, 5,5\%, 14,7\% foram identificados como pobres de acordo com as linhas estimadas no presente estudo. São discutidas as implicações para as políticas públicas.
\end{abstract}

Palavras-chave: Linhas de Pobreza; Pobreza; Pesquisa de Orçamentos Familiares; Brasil.

\begin{abstract}
New estimates of poverty lines in Brazil are provided based on consumption data from the 2008-2009 Household Budget Survey (POF). A consistent methodology - with imputations for measurement error and durable goods services - is presented for the estimation of three lines: a food (extreme) poverty line, and lower and upper poverty lines adjusted for non-food items. While only $2.1 \%$ and $10.7 \%$ of the population were considered extremely poor and poor according to the administrative lines used for Bolsa Famíla, 5.5\%, 14.7\% and 36.2\% were identified as poor based on the poverty lines estimated here. Implications for public policy are discussed.
\end{abstract}

Keywords: Poverty; Poverty Lines; Household Budget Survey (POF); Brazil. JEL classification: I3

DOI: http ://dx.doi.org/10.11606/1980-5330/ea150617

\footnotetext{
* Professora Adjunta do Departamento de Economia na Universidade Federal de Viçosa. Email: cristiana.rodrigues@ufv.br.

† Professor associado de Economia na Universidade da Califórnia, Riverside. Email: steven.helfand@ucr.edu.

‡ Professor Titular do Departamento de Economia Rural na Universidade Federal de Viçosa. Email: jelima@ufv.br.
} 


\section{Introdução}

A pobreza define-se, normalmente, como a insuficiência de recursos para assegurar as condições básicas de subsistência e de bem-estar dos indivíduos em uma sociedade. Uma linha de pobreza irá permitir a uma sociedade considerar como pobres todos aqueles indivíduos que se encontrem abaixo do seu valor (Barros et al. 2000).

No Brasil, não existe uma linha oficial de pobreza. Encontra-se uma grande variedade de linhas de pobreza utilizadas tanto em trabalhos aplicados como para programas de redução da pobreza (Figueiredo et al. 2007). A análise a partir da insuficiência de renda é uma das principais e mais difundidas formas de mensuração da pobreza. Como a maioria dos estudos sobre pobreza no Brasil utilizam dados da Pesquisa Nacional de Amostra por Domicílio (PNAD), a abordagem da renda tem sido a abordagem mais comum nos estudos de pobreza no Brasil.

De acordo com Fields (2001), podem-se distinguir quatro categorias de linha da pobreza. A primeira abordagem define a linha da pobreza como um nível arbitrário da renda, por exemplo, como uma percentagem do salário mínimo, seus valores são apenas ajustados pela inflação. Alguns autores definiram a linha de pobreza dessa forma, por exemplo, Hoffmann (2000), que define a linha de extrema pobreza como $1 / 4$ do salário mínimo (s.m.) per capita e a linha de pobreza como $1 / 2$ s.m. per capita, e Corrêa (1998) que usa $1 / 2$ e 1 s.m. per capita, respectivamente. Assim, o fato do nível ser arbitrário e a não consideração de diferenças no custo de vida entre as regiões e áreas rurais e urbanas, caracterizam-se como algumas falhas do método, bem como a taxa, relativamente alta, de subdeclarações de renda. Rocha (1996) argumenta que esse método tende a superestimar a pobreza nas zonas rurais e subestimar em áreas urbanas.

As linhas de pobreza internacionais são a segunda classe de linhas de pobreza e são geralmente definidas para comparações de pobreza entre países, como, por exemplo, no contexto dos objetivos de Desenvolvimento do Milênio. Essa linha é obtida convertendo uma linha de pobreza internacional extrema e completa de US $\$ 1,00$ e US $\$ 2,00$ por dia per capita para a moeda nacional, com ajustamentos de paridade de poder de compra (PPC) ${ }^{1}$. Um exemplo de análise da pobreza no Brasil que usa esse tipo de linha de pobreza é a CEPAL (2002). Embora essa abordagem seja importante para estabelecer comparações internacionais, não permite que as linhas reflitam padrões de consumo e os preços dos bens em um país como o Brasil.

Uma terceira abordagem considera um fator subjetivo para detectar como as famílias avaliam suas próprias condições de vida. A definição comumente utilizada para a pobreza subjetiva é o sentimento que não se tem o suficiente para seguir adiante. Nesse sentido, Crespo \& Gurovitz (2002) chamam a atenção para o fato de que é preciso ouvir dos pobres os que eles pensam sobre a sua condição de pobreza.

A quarta abordagem, que o Fields (2001) aponta, baseia-se no consumo. Nos estudos de Deaton (1997) e Deaton \& Zaidi (2002), afirma-se que a estru-

\footnotetext{
${ }^{1}$ A linha de pobreza de US\$ 1,00 per capita, por dia - ao PPP de 1985 - foi originalmente proposta porque representava uma média das linhas de pobreza em 33 países de baixa renda. Essa linha era vista como uma linha de pobreza típica para alguns dos países mais pobres do mundo. Esse valor tem aumentado ao longo do tempo por duas razões: o valor das linhas de pobreza nos países pobres tem aumentado, e a taxa PPP tem mudado (Chen \& Ravallion 2008).
} 
tura de consumo das famílias é a fonte mais adequada para o estabelecimento de linhas de pobreza. Esses autores apontam algumas vantagens de se utilizar os gastos em consumo, em vez da renda, como medida de bem-estar. Argumentam que o consumo é uma melhor medida do bem-estar no longo prazo, visto que a renda apresenta maiores flutuações no curto prazo. O consumo também capta o bem-estar mais precisamente do que a renda, desde que seja uma medida mais apropriada de oportunidades de bem-estar. Além disso, os gastos de consumo refletem não apenas o que um agregado familiar pode fazer com sua renda, mas também se tem acesso aos mercados de crédito. Assim, esses seriam um dos pontos favoráveis para eleição do consumo como indicador do nível de bem-estar dos agregados familiares (Quintães et al. 2006).

Alguns trabalhos têm utilizado o consumo da Pesquisa de Orçamento Familiar (POF) para definição da linha de pobreza. No Brasil, podem-se destacar os trabalhos de Rocha $(2000,2006)$ que muito têm contribuído para construção e aperfeiçoamento das linhas de indigência e pobreza que levam em conta as especificidades das cestas de consumo e alimentares locais. Já na literatura internacional, destaca-se Bank (2006), que explicita uma metodologia para levar em conta as diferenças de custo de vida entre as regiões brasileiras, bem como entre áreas urbanas e rurais, na construção das linhas de pobreza.

Entretanto, os dados mais recentes que esses trabalhos utilizaram foram da POF 2002-20032 . Portanto, torna-se oportuno, com a disponibilização dos dados da POF 2008-2009, a estimação de novas linhas da pobreza que considerem na sua definição as especificidades da cesta de consumo. Utiliza-se para isso uma metodologia clara e consistente, que reflete as diferenças regionais do custo de vida e vai-se além da simples definição de um ponto de corte arbitrário $^{3}$. Os procedimentos adotados permitem traçar um perfil de pobreza com base na definição de três linhas de pobreza diferentes, a linha de extrema pobreza, que é linha de pobreza de alimentos, e duas linhas para considerar as necessidades básicas com itens não alimentícios, sendo uma linha mais baixa e outra mais alta. Além disso, permite-se construir linhas de pobreza para as diferentes regiões do Brasil, podendo assim captar a variação espacial no custo de vida e fornecer um perfil da pobreza atualizado para as regiões.

Diante dessas considerações, este trabalho tem como objetivo principal contribuir para aperfeiçoamento das estimativas de linhas de pobreza no Brasil, com base nos dados de consumo das Pesquisas de Orçamento Familiar, POF 2002-2003 e POF 2008-2009, e na utilização de técnicas para melhoria da qualidade dos mesmos. Esse tipo de análise é importante, pois permite, a partir de dados concretos de consumo, entender como escolhas metodológicas podem influir no valor final do parâmetro obtido para medida de bem-estar, que irão ter consequências diretas nas estimativas de incidência de pobreza no Brasil.

Este artigo está divido em 5 seções. Além desta introdução, uma segunda seção em que são descritos os procedimentos adotados para construção do agregado de consumo e estimação das distintas linhas de pobreza. Na terceira seção, apresentam-se as linhas de pobreza; na quarta seção, quantifica-se como irão variar as taxas de pobreza considerando cada uma dessas linhas e

\footnotetext{
${ }^{2}$ As fontes de dados disponíveis eram ENDEF 1974-1975, POF 1987-1988, POF 1995-1996 e POF 2002-2003.

${ }^{3} \mathrm{O}$ conceito de consistência requer que a linha de pobreza real, definida como a linha de pobreza nominal depois do ajustamento das diferenças de custo de vida entre regiões, seja a mesma para todas as regiões (Bank 2006).
} 
apresenta-se uma discussão sobre os pobres e vulneráveis com base nas novas linhas estimadas. Por fim, tem-se a conclusão na quinta seção.

\section{Metodologia}

Esta seção visa descrever os procedimentos adotados para estimação das linhas de pobreza de consumo. Para definir a linha de pobreza alimentar, primeiramente, explicam-se os procedimentos adotados para realizar a agregação dos itens alimentares, que irão compor a cesta de necessidades básicas, e os itens não alimentares. Em seguida, apresenta-se a metodologia utilizada para lidar com erros de mensuração da POF, a qual permite realizar imputação para gastos zero e anômalos, bem como a metodologia para melhorar a qualidade dos dados por meio da construção e imputação do fluxo de bens duráveis. Por fim, apresenta-se a metodologia para estimação da linha de pobreza extrema e a metodologia para ajustar essa linha de duas formas diferentes para estimar as linhas de pobreza baixa e alta.

\subsection{Procedimentos de agregação dos itens alimentares na Pesquisa de Orçamento Familiar para compor a cesta das necessidades básicas}

A Pesquisa de Orçamentos Familiares capta durante sete dias as despesas de alimentos das famílias, tanto coletiva quanto individual ${ }^{4}$. Para a análise de bem-estar, os produtos de alimentação são de particular importância, pois estratos de renda mais baixa tendem a gastar uma parcela considerável do seu orçamento nesses produtos. Assim, entende-se que o grupo alimentação pode ser incluído integralmente no consumo agregado, visto que este constitui uma parcela primordial no consumo total das famílias (Quintães et al. 2006).

A literatura recomenda, na computação de uma medida de consumo total de alimentos, para fazer parte da medida de bem-estar agregado, a inclusão dos alimentos consumidos pelos domicílios por meio de todas as fontes possíveis: como os alimentos que foram comprados no mercado; os alimentos que são produzidos em casa; os alimentos recebidos como presentes ou doações; e os alimentos recebidos como pagamento em espécie por serviços (Deaton \& Zaidi 2002). O valor total das refeições consumidas fora de casa (restaurantes, alimentos preparados comprados no mercado local, refeições realizadas na escola, no trabalho, durante as férias, etc.) deve também ser incluído no agregado de consumo de alimentos.

As dificuldades encontradas na construção de um agregado não alimentar total anual encontram-se na escolha de quais itens serão incluídos. Portanto,

\footnotetext{
${ }^{4}$ Embora muitas vezes se utilize o termo família, o IBGE faz uma diferenciação entre "família" e "domicílio". O conceito "família", no IBGE refere-se a todas as pessoas moradoras do domicílio, ligadas por laços de parentesco, dependência doméstica ou normas de convivência, sem referência explícita ao consumo ou despesas. No domicílio, por sua vez, é identificada a unidade básica da pesquisa - unidade de consumo - que compreende um único morador ou conjunto de moradores que compartilham da mesma fonte de alimentação ou compartilham as despesas com moradia. Entretanto, na maior parte das situações, a unidade de consumo da POF coincide com a "família", segundo o conceito adotado no IBGE. A POF 2008-2009, buscando harmonização conceitual com as demais pesquisas, identificou, também, nos domicílios, as famílias, segundo o conceito adotado pelo IBGE. Os cálculos realizados neste estudo se deram com base nos cálculos dos valores per capita dos domicílios.
} 
um primeiro passo para construção do agregado de consumo é definir quais tipos de despesas serão incluídas e excluídas em cada grupo. A escolha depende não só dos dados disponíveis, mas também do objetivo analítico do estudo realizado (Deaton \& Zaidi 2002). A maioria dos bens e serviços, que constam na POF, é classificada como itens não alimentícios. Nessa categoria, há um grande número de itens que claramente fazem parte de medida de bem-estar, tais como higiene e limpeza, serviços domésticos, habitação, serviços pessoais, lazer, papelaria, jornais e revistas, entretenimento, eventos desportivos, vestuário, etc. Porém, nem todas as despesas que constam nesses registros devem ser incluídas no agregado de consumo. Para os bens que podem representar uma necessidade "lamentável $\mathrm{l}^{5 "}$, como as despesas de negócios e de serviços que podem ser mais um investimento, os impostos e taxas de serviços e itens de consumo anormal e irregular, se faz necessário uma discussão sobre a validade de incluí-los na medida de consumo agregado (Figueiredo et al. 2007).

Para construir o agregado de consumo total com itens não alimentícios para mensuração do bem-estar das famílias, soma-se o total dos gastos nos itens incluídos em cada um dos grupos que fazem parte desse agregado, são eles: habitação, transportes, saúde e cuidados pessoais, educação, vestuário, recreação e cultura, fumo, serviços pessoais e despesas diversas ${ }^{6}$. Esses grupos são descritos em mais detalhes abaixo.

O item habitação possui a maior participação dentro da cesta de consumo das famílias, tanto na POF 2002-2003 como na POF 2008-2009, e, portanto, tem significativa importância na análise do bem-estar. Nesse grupo, são investigados sete tipos de despesas relacionadas à habitação: aluguel; serviços de utilidade pública; reformas do lar; mobiliários e artigos do lar; serviços e taxas, eletrodomésticos e consertos de eletrodomésticos; e artigos de limpeza. Para cálculo do consumo agregado em habitação, utilizam-se as despesas para manutenção do domicílio, como as diversas despesas com conta de energia, água e esgoto, telefone, combustíveis domésticos, material de construção e manutenção etc. Utilizam-se também as despesas diversas com o imóvel, aluguel pago e estimado, condomínio, impostos sobre imóveis, taxas diversas sobre serviços, despesas com jardinagem e material de limpeza, as despesas referentes à artigos do lar e, por fim, as despesas com serviços domésticos.

$\mathrm{Na}$ construção do agregado de consumo com transportes incluem-se todos os itens relacionados às despesas com transporte em geral, como estacionamento, seguros, manutenção do veículo e acessórios, óleo, lubrificação e alinhamento de pneus, gasolina, despesas com viagens esporádicas etc. Em contrapartida, excluem-se os gastos associados à compra, melhoria substancial ou grandes reparos de veículos, despesas irregulares, que são mais adequadamente vistas como investimento do que consumo.

No grupo de saúde e cuidados pessoais, encontram-se as despesas com higiene e cuidados pessoais, assistência à saúde, remédios e plano de saúde. Em geral, na construção do agregado de saúde os gastos com saúde devem ser excluídos porque são uma necessidade "lamentável" - a inclusão destes poderia fazer pessoas mais doentes aparecerem em melhor situação - e também porque eles podem ser muito irregulares e os seus preços poderão ser

\footnotetext{
5 “Necessidades lamentáveis” são gastos com bens ou serviços não desejados, mas necessários, seja para trabalho, por exemplo, as roupas ou o transporte, ou para resolver algum infortúnio.

${ }^{6} \mathrm{~A}$ maior parte das decisões sobre quais itens são incluídos ou excluídos de cada grupo de consumo baseou-se em Deaton \& Zaidi (2002).
} 
subsidiados em níveis extremamente variáveis, seja por seguros privados ou públicos, de modo que os preços pagos são um reflexo muito impreciso do valor dos serviços (Deaton \& Zaidi 2002). A maioria dos produtos farmacêuticos é para tratamento de problemas médicos e da mesma forma devem ser excluídos. No entanto, a lista de produtos farmacêuticos também inclui itens que são destinados à saúde preventiva em geral, conforto, conveniência ou de planejamento familiar e, portanto, devem-se ser incluídos no total do consumo, assim como as despesas com cuidados pessoais, complexos vitamínicos e fortificantes.

Na construção do agregado de consumo, Deaton \& Zaidi (2002) recomendam a inclusão dos gastos com educação, que constituem os gastos com cursos regulares, superiores, outros cursos e atividades, livros didáticos e revistas técnicas, artigos escolares e outros. Apesar de serem gastos irregulares, eles são importantes porque estão concentrados nos anos mais jovens da vida de uma pessoa.

No agregado de consumo com vestuário são incluídas todas as despesas com roupas de homem, roupas de mulher, roupas de criança, calçado, tecido e armarinho, bem como despesas com jóias, relógios, bijuterias e apetrechos.

No agregado de consumo com recreação e cultura foram incluídos os gastos com brinquedos e jogos, celulares, instrumentos musicais e acessórios, periódicos, livros e revistas não didáticos, recreação e esportes e outros, gastos com celulares e acessórios, baterias, selos para coleção, tintas para pintura, despesas com viagens, cinemas, shows, atividades recreativas, etc.

No agregado de consumo com fumo incluem-se as despesas diversas com fumo, sendo todas incluídas no agregado de consumo. Entre as despesas incluídas no agregado de consumo com serviços pessoais, encontram-se os gastos com cabeleireiro, manicuro e pedicuro, concertos de artigos pessoais, massagem, esteticista e outros serviços pessoais. No agregado de despesas diversas encontram-se as despesas com jogos e apostas, comunicação (correios, gastos com telefones públicos e acesso à internet fora do domicílio) e cerimônias e festas, gastos com animais e serviços profissionais como cartório. No caso das despesas com festas, não se utiliza todos os itens, apenas os que podem ocorrer com maior frequência, tais como festas de aniversário. Com relação aos gastos em cerimônias, deve-se incluir todos os itens, exceto aqueles que acontecem raramente, que são cerimônias como casamentos, funerais, etc. (Figueiredo et al. 2007).

Os dados de compras de itens não alimentícios são frequentemente coletados para diferentes períodos recordatórios, sendo assim, na construção de um agregado não alimentar, todas as quantidades informadas devem ser convertidas para um período uniforme de referência, no caso deste trabalho, converteu-se todas as despesas em valores mensais.

\subsection{Lidando com erros de mensuração de alimentos na POF}

As informações sobre gastos alimentares na POF são captadas em um período de referência de 7 dias, o mais curto na pesquisa. Por essa razão, é susceptível de conduzir a uma quantidade considerável de erros de mensuração nos domicílios que não compram alimentos com muita frequência. Constatou-se que na POF 2002-2003 existiam 1749 domicílios (3,6\%) que não apresentam relatos sobre despesa com alimentos e 3241 domicílios $(5,79 \%)$ na POF 2008 2009. Entre aqueles domicílios com baixos rendimentos, para os quais gastos 
alimentares são particularmente importantes, a presença dos gastos nulos no consumo de alimentos é suscetível de conduzir à subestimação do bem-estar das famílias, o que tem consequências diretas para estudos de pobreza, pois causará uma sobre estimação de pobreza global e dificultará a distinção entre os pobres e não pobres.

Lanjouw (2005), Bank (2006) e Figueiredo et al. (2007) propõem métodos diferentes para tentar resolver esse problema. Lanjouw (2005) propõe uma técnica de corte que consiste em eliminar da amostra os valores extremos do consumo agregado. A abordagem utilizada pelo Bank (2006) permite fazer uma imputação para os domićlios que apresentam gastos alimentares com valor zero, baseado em um modelo de regressão linear para as despesas de alimentação em função de um conjunto de características sociodemográficas observáveis nas famílias. Porém, os métodos propostos lidam com apenas uma parte do problema. Eles lidam apenas com os casos extremos de consumo zero em alimentos. Uma vez que o problema do erro de mensuração depende da frequência da compra de alimentos, casos muito diversos de registros imprecisos de despesas com alimentos - subestimação e superestimação - podem surgir. A fim de abordar essas diferentes fontes de má mensuração em alimentos, Figueiredo et al. (2007) propõem um método que busca identificar as situações, além dos gastos zero com alimentos, para as quais o erro de mensuração é também provável de ocorrer. Neste estudo, será utilizada a abordagem proposta por Figueiredo et al. (2007), a qual está descrita abaixo.

Analisando-se algumas perguntas subjetivas, respondidas pelos moradores dos domicílios sobre "Condições de Vida", podem-se identificar as famílias para as quais o erro de mensuração em gastos com alimentação é mais provável de acontecer. A primeira pergunta subjetiva é "qual seria o custo mínimo para fornecer uma quantidade suficiente de alimentos para o domicílio, em um dado mês". A segunda é uma avaliação subjetiva do consumo mensal de alimentos com três possíveis respostas: "normalmente é insuficiente", "às vezes é insuficiente" e "é sempre suficiente". Comparando a resposta numérica para a primeira pergunta com os valores observados para as despesas de alimentação na POF, podem-se deduzir algumas possíveis inconsistências nos dados apresentados, dada a resposta do domicílio à segunda questão. Para as famílias cujo consumo alimentar normalmente não é suficiente, uma despesa com alimentação que é muito maior do que a família considera como custo mínimo de aquisição de uma quantidade adequada de alimentos, indica que o que a família comprou de alimentos na semana de referência não é representativo do gasto semanal em uma semana regular. Nesse caso, o que pode ter ocorrido é que uma grande compra de alimentos para um período longo de tempo, geralmente um mês, ocorreu na semana em que o questionário foi preenchido. Assim, as despesas com alimentos registradas podem estar superestimando as despesas usuais com alimentação. Por outro lado, podemos ter um cenário no qual as despesas com alimentos são muito mais baixas do que a quantidade considerada como a mínima suficiente, para uma família que relatou normalmente ter uma quantidade adequada de alimentos. Uma possível explicação para esse caso é que nenhuma ou pouca compra de alimentos ocorreu na semana em que o questionário foi preenchido, mas provavelmente ocorreram em uma semana diferente, apresentando assim erro de mensuração nos dados. Como resultado poderá haver uma subestimativa dos gastos normais em alimentos (Figueiredo et al. 2007).

Para correção das possíveis fontes de viés, utiliza-se a relação entre as des- 
pesas mensais em consumo de alimentos (despesa observada com alimentos) sobre a despesa mínima mensal com alimentação, considerada adequada pela família (despesa de alimentos necessária). Em termos da especificação da regressão de imputação, faz-se a regressão da despesa com alimentos contra algumas características das famílias utilizando as observações para as quais o consumo de alimentos é menos provável de apresentar erros de medição. A forma geral do modelo é o seguinte:

$$
\ln \left(F_{h}\right)=\alpha+\beta \ln N F_{h}+\gamma Z_{h}+\epsilon_{h}
$$

em que $F_{h}$ e $N F_{h}$ são gastos per capita em alimentos e gastos per capita em não alimentos para o domicílio $h$. Na Equação (1), assume-se a tradicional especificação logarítmica da função de demanda; $Z_{h}$ é o conjunto de variáveis de controle presentes na base de dados da POF; e $\epsilon_{h}$ é o termo de erro aleatório não observável. As variáveis explicativas são os seguintes:

- variável de identificação da área de localização do domicílio (rural e urbano);

- total de pessoas no domicílio;

- características do chefe de família (sexo, raça, cor, idade);

- dummies de escolaridade do chefe (1 a 4 anos de estudo, 4 a 8 anos, 8 a 12 anos, e mais de 12 anos);

- dummy para identificar se a ocupação do chefe é remunerada;

- dummies para os diferentes tipos de ocupações (empregado, empregador, empregado temporário rural, conta própria, trabalhador para consumo próprio, trabalho não remunerado);

- características demográficas das famílias também são incluídas no modelo: a participação no total de pessoas no domicílio de crianças e adolescentes, menores de 18 anos de idade, adultos com idade maior que 18 e menor que 59 anos, e idosos com idade maior que 60 anos.

Os resultados das regressões estimadas encontram-se nas Tabelas 5 e A. $1^{7}$. Usam-se os coeficientes estimados para predizer o consumo alimentar para todos os domicílios para os quais o valor da despesa em alimentação é provável de se apresentar erros de mensuração.

A primeira questão é definir um caminho para avaliar quais observações de despesas de alimentos devem ser considerados como anômalas e, consequentemente, devem ser excluídas da amostra a ser utilizada nas regressões. Primeiramente, calcula-se a despesa total mensal em alimentos deflacionada para cada domicílio ("despesa observada de alimentos"). Em seguida, calculam-se os valores mensais deflacionados para as respostas subjetivas à pergunta sobre o gasto mínimo mensal com alimentação considerado adequado pela família, a fim de se obter a variável "despesa de alimentos necessária". Finalmente, divide-se a "despesa observada de alimentos" pela "despesa de alimentos necessária" para, dessa forma, se obter a variável "razão alimentar". A partir da

\footnotetext{
${ }^{7}$ Serão exibidas no apêndice somente as tabelas de resultados da POF 2008-2009. As tabelas para POF 2002-2003 estão disponíveis nos autores.
} 
"razão alimentar" podem-se identificar os possíveis casos anômalos. A estimação da equação do consumo de alimentos contra algumas características das famílias deverá conter apenas os domicílios que não são prováveis de apresentar erros de mensuração ou serem anômalos. Todos os domicílios que são excluídos da amostra, na estimação da Equação (1), serão imputados posteriormente.

Três abordagens alternativas são propostas para identificar as famílias com possíveis erros de mensuração. As abordagens utilizam pesos que classificam as famílias como tendo erros, não tendo erros, ou, eventualmente, tendo erros com diferentes graus de certeza (ver Tabela 1). O primeiro vetor de pesos, peso 1 , será igual a zero sempre que a despesa em alimentação for igual a zero, e será igual a 1 caso contrário. Considerando-se que gasto nulo é implausível mesmo para domicílios muito pobres, a imputação é realizada para todos os domicílios que apresentam gasto zero. Na definição dos pesos 2 e 3, primeiramente, define-se que estes pesos são iguais a zero naqueles domicílios em que a despesa com alimentos é igual a zero. Em seguida, a partir das questões subjetivas sobre as condições de vida, identificam-se diferentes tipos de peso para cada tipo de situação alimentar no domicílio. A diferença entre o peso 2 e peso 3 é que peso 2 assume apenas valores 1 ou zero, ou seja os domicílios têm dados que são corretos ou incorretos. Se incorretos, o domicílio não é usado na análise de regressão e usa-se a regressão para predizer valores para os mesmos. Já no caso do peso 3, os domicílios podem assumir pesos menores que um, refletindo o grau de certeza que há sobre a precisão da observação. Assim, aqueles domicílios que podem ter anomalias têm pesos entre zero e um.

Tabela 1: Tipos de pesos de acordo com cada tipo de situação alimentar no domicílio

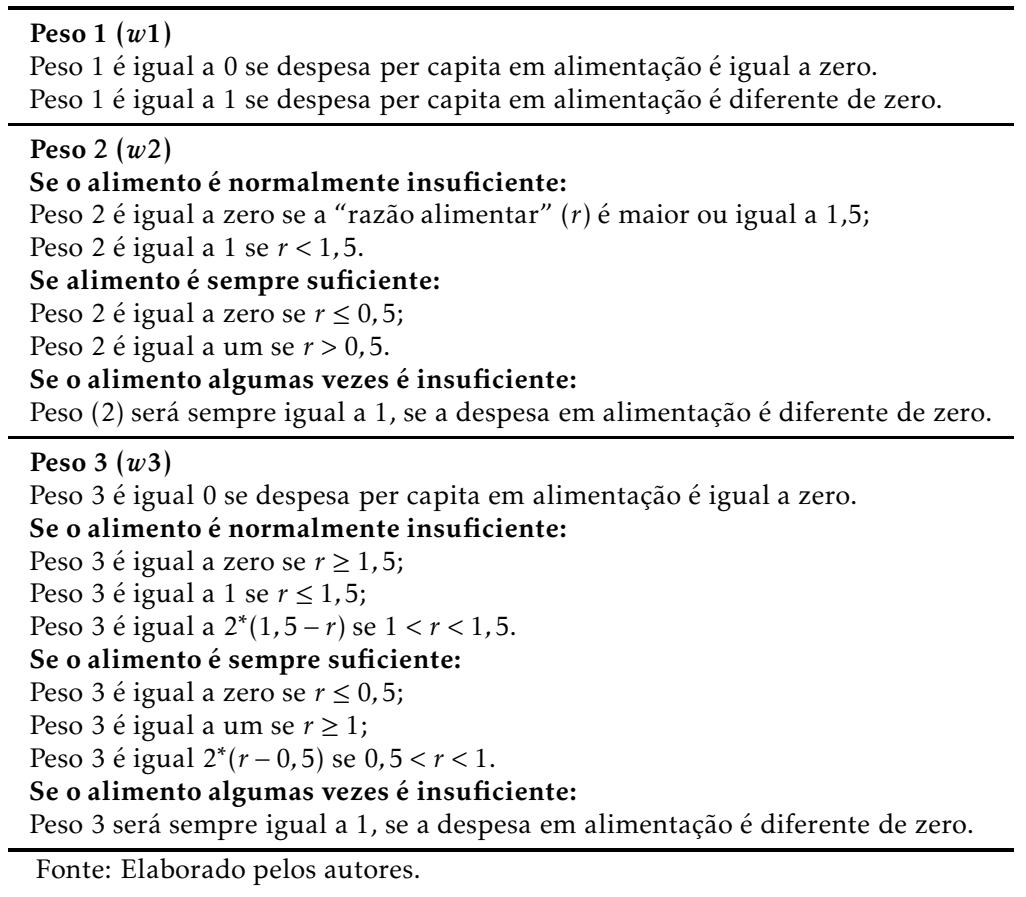


A abordagem geral consiste em estimar a Equação (1) três vezes - com $w_{1}$, $w_{2}$, e $w_{3}$ - e usar os coeficientes dos três modelos para predizer consumo de alimentos para todo domicílio para o qual o valor observado é provável de apresentar erros de mensuração. A Equação (2) mostra que a forma em que a imputação é realizada varia com o peso. A medida imputada de alimentos $\left(\tilde{F}_{h}\right)$ será dada pela média ponderada do valor predito $\left(\hat{F_{h}}\right)$, e o declarado $\left(F_{h}\right)$. A equação é calculada para cada um dos três casos de erro de mensuração.

$$
\tilde{F}_{h}=w_{h} F_{h}+\left(1-w_{h}\right) \hat{F_{h}}
$$

em que $w$ é representado pelos três pesos definidos anteriormente.

Nota-se que após a imputação, em ambas as pesquisas, há um aumento na média de despesa em alimentação em todos os modelos. Esses resultados de aumento na despesa média após a imputação eram esperados, uma vez que é mais provável que haja aumento da despesa média, já que as despesas em alimentação de 21,06\% (POF 2002-2003) e 27,72\% (POF 2008-2009) dos domicílios foram consideradas como subestimadas, enquanto que apenas 1,62\% (POF 2002-2003) e 0,91\% (POF 2008-2009) dos domicílios foram considerados como tendo uma sobre estimativa em despesa de alimentação. O resultado de aumento na despesa média após a imputação é óbvio para o caso no qual a imputação ocorre apenas para domicílios com despesa zero em alimentos. (Os resultados das despesas médias com alimentação dos modelos de imputação encontram-se na Tabela A.2). Todos os resultados apresentados neste trabalho utilizam o agregado de consumo calculado com imputação usando o Peso $3^{8}$, para corrigir os possíveis gastos anômalos no domićlilio. Consideramos que o peso 3 seja o mais apropriado, já que também atribui pesos aos domicílios que podem ter anomalias.

\subsection{Construção e imputação do fluxo de bens duráveis}

Bens de consumo duráveis são frequentemente apontados como um importante componente da riqueza das famílias. Porém, não se deve simplesmente adicionar gastos em bens-duráveis durante o período de referência diretamente ao agregado de consumo ${ }^{9}$. O correto é adicionar um fluxo de serviço ao agregado de consumo, o qual é imputado a partir da informação disponível sobre idade, propriedade e valor de reposição dos bens de consumo duráveis. Isto é especialmente importante para itens de valor maior como geladeira, carro, fogão, ou máquina de lavar. Estes são gastos tipicamente grandes que ocorrem muito raramente, e a inclusão de tais gastos no agregado de consumo pode gerar distorções no bem-estar das famílias. Assim, um método que tenta captar o valor desses serviços, mesmo tendo que estabelecer alguns pressupostos na computação do fluxo de serviços para os bens incluídos no inventário, ainda é melhor do que ignorar essas mercadorias completamente (Figueiredo et al. 2007).

Na POF, apesar de haver uma seção sobre o inventário dos bens duráveis para os domicílios, o questionário não inclui informações sobre o valor de compra original ou valor de reposição atual, as quais possibilitam o cálculo

\footnotetext{
${ }^{8}$ Como se optou por utilizar o agregado de consumo calculado com imputação do Peso 3, apresentou-se somente os resultados referentes aos mesmos.

${ }^{9}$ Para maiores explicações sobre diferenças importantes causadas no bem-estar das famílias pela não inclusão do valor de aquisição com despesas irregulares em itens duráveis no consumo agregado ver Bank (2006).
} 
do fluxo de serviços dos bens duráveis. Desde que a seção da POF que lida com bens duráveis não fornece todas as informações necessárias para calcular "o valor de serviço" dos bens duráveis, muitos autores (Quintães et al. (2006) e Bank (2006)) decidiram não incluir bens duráveis no cálculo do agregado de consumo.

Entretanto, a questão que se coloca é se é melhor excluir os bens duráveis do agregado de consumo ou se é melhor estimar os custos implícitos de seu uso com alguns pressupostos razoáveis (Figueiredo et al. 2007). A presença ou ausência de bens duráveis pode indicar diferenças importantes no bem-estar das famílias. Por essa razão, utiliza-se de um método que tenta captar o valor desses serviços. Para computar o fluxo de serviços $\left(S_{i t}\right)$ em bens de consumo duráveis, utiliza-se a metodologia dada por Deaton \& Zaidi (2002):

$$
S_{i t}=V_{i t}\left(r_{t}-\pi_{t}+\delta\right)
$$

em que $V_{i t}$ é o valor corrente do bem durável $t ; r_{t}-\pi_{t}$ é a taxa real de juros dada pela taxa nominal de juros $\left(r_{t}\right)$ e a taxa de inflação $\left(\pi_{t}\right)$ e $\delta$ é a taxa de depreciação para os bens duráveis.

Dada a falta de informação relatada para o valor corrente dos bens duráveis no inventário, utiliza-se o valor dos bens novos comprados durante o período de referência para determinar o valor corrente no ano de referência, aplicando-se a taxa de depreciação.

$$
S_{i t}=V_{i 1}(1-\delta)^{\alpha_{i}}\left(r_{t}-\pi_{t}+\delta\right)
$$

Assim, o valor corrente dos bens duráveis $i$ é dado por $V_{i 1}(1-\delta)^{\alpha_{i}}$, em que $V_{i 1}$ é o valor original do bem e $\alpha_{i}$ é o número de anos desde que o bem foi adquirido. Desde que a taxa de juros flutua amplamente, assumiu-se que a taxa de juros real é constante sobre o tempo e igual a 5\%. A depreciação é fixa em $10 \%$. $V_{1}$ é o preço de compra ou o valor inicial, que é dado pela média do preço de itens na mesma categoria, comprados novos com dinheiro ou crédito, conforme registrado nas diferentes seções da pesquisa.

A idade de cada item $\alpha_{i}$ é determinada usando o número de anos desde que o domicílio adquiriu o item mais a idade média (metade da vida útil esperada) se o item foi reportado como usado quando o domicílio adquiriu (ou se as condições são desconhecidas). Em vez de escolher uma vida útil específica para todos os diferentes bens duráveis, utilizam-se 3 diferentes categorias para os itens no inventário: 5 anos para computador, secador e outros eletrônicos que costumam não ter longa durabilidade; 10 anos para itens eletrônicos mais duráveis, como televisores, rádio, geladeira, freezer, máquina de lavar, máquina de secar, etc.; 15 anos para veículos, bicicleta, motocicleta, máquina de costura e antena parabólica. Os valores dos fluxos de serviços mensais para os bens duráveis incluídos no inventário para POF 2008-2009 encontram-se na Tabela A.3.

\subsection{Estimação da linha de pobreza alimentar}

Para definir a linha de pobreza alimentar, primeiramente, um grupo de referência da população é escolhido para determinar a composição da cesta de ali- 
mentos das necessidades básicas ${ }^{10}$. A população de referência escolhida para determinar a cesta de necessidades básicas é o conjunto de famílias compreendido entre o 20o e o 40o percentis da distribuição do total de gastos per capita. (Informações adicionais sobre a distribuição do total de gastos per capita das famílias no percentil de 20 a 40 para o Brasil, POF 2008-2009, encontram-se Tabela A.4). Não há um critério fixo para escolha da população de referência, mas essa população deve ter uma cesta de consumo representativa das necessidades básicas e deve estar próxima ao limiar da pobreza. Para se possibilitar comparações, optou-se por utilizar os mesmos percentis da distribuição utilizado pelo Bank (2006). Segundo, a cesta de alimentos de necessidades básicas é construída considerando três propriedades: (i) a composição da cesta reflete a variedade de itens alimentícios consumidos por uma população de referência, perto do limiar esperado para pobreza; (ii) ela deve prover as exigências de energia de alimentos de 2300 kcal per capita por dia ${ }^{11}$; e (iii) as recomendações calóricas são derivadas de uma variedade suficientemente diversa de alimentos (por exemplo, um pouco de carne e frutas e legumes e não apenas arroz e outros cereais).

Seguindo os procedimentos adotados por Bank (2006), dado o grande número de itens alimentares presentes na POF, a seleção dos itens alimentares específicos que compõem a cesta básica de necessidades foi realizada com base nas seguintes etapas. Em primeiro lugar, os 5.442 diferentes itens foram primeiramente agrupados em 41 grupos de alimentos (isto é, cereais, feijão, legumes, etc). Segundo, a escolha de itens específicos de alimentos é realizada selecionando itens alimentares mais frequentemente comprados nos grupos de alimentos pelas famílias da população de referência. A resultante cesta de necessidades básicas de consumo de alimentos tem 26 itens de alimentos específicos $^{12}$.

Em seguida, as quantidades foram expressas em termos per capita e por dia, sendo divididas pelo número de membros do agregado familiar residente no domicílio e pela média de dias nos meses do ano (30,4 dias). A quantidade média de cada um dos itens que compõe a cesta de alimentos foi redimensionada para garantir que a cesta de alimentos gere $2.300 \mathrm{kcal}$ per capita por dia. Esse procedimento foi realizado pela multiplicação da quantidade média $^{13} \mathrm{em} \mathrm{kg}$ de cada um dos itens alimentares por um fator de conversão $(k)$ (ver colunas d e e, Tabela A.5. Esse fator é fixo e é obtido a partir da razão entre exigência calórica diária recomendada (Organização para Agricultura e Alimentação (FAO)) per capita e o total de calorias geradas pelas quantidades

\footnotetext{
${ }^{10}$ A linha de pobreza alimentar é também definida como a linha de extrema pobreza, pois abaixo desse limiar as famílias não são capazes nem de satisfazer as suas necessidades básicas em alimentos.

${ }^{11}$ Segundo a Organização para Agricultura e Alimentação (FAO) a exigência calórica média diária requerida para o Brasil é estimada em $2.300 \mathrm{kcal}$ per capita por dia. É importante ter em mente que a fixação de exigência de energia de alimentos de 2.300 kcal per capita por dia é uma media, já que as necessidades energéticas de alimentos variam de acordo com idade, sexo e nível de atividade física.

${ }^{12}$ Os itens de alimentos selecionados para compor a cesta de pobreza incluem: arroz, feijão, refrigerante, tomate, cebola, batata inglesa, banana, farinha de mandioca, farinha de trigo, fubá de milho, macarrão, pão francês, biscoito, carne de boi de primeira, carne de boi de segunda, carne suína, frango, ovo de galinha, leite, queijo, açúcar, chocolate em pó, óleo de soja, margarina, embutido e café. O agrupamento de cada um dos itens alimentícios que compõem a cesta seguiu as categorias descritas pelo IBGE (2004).

${ }^{13}$ As médias das quantidades foram obtidas por meio do cálculo das quantidades médias per capita e por dia consumidas de cada um dos produtos que compõem a cesta para a população.
} 
médias per capita por dia na cesta de pobreza. Os fatores de conversão calculados para a POF 2002-2003 e para POF 2008-2009 são de 0,5844 e 0,5672, respectivamente. O valor encontrado por Bank (2006), usando dados da POF 2002-2003 foi de 0,59.

O próximo passo consiste em estimar a linha de pobreza para cada região pela valoração da cesta de necessidades básicas separadamente em cada região. Especificamente, a linha de pobreza alimentar em cada macrorregião e áreas urbanas e rurais $\left(F P L^{R}\right)$ é estimada usando a expressão:

$$
F P L^{R}=\sum_{i=1}^{n} p_{i}^{R}\left(q_{i}^{0} \times k\right)
$$

em que o sobrescrito $R$ denota as diferentes macrorregiões do país e áreas rurais e urbanas, $p_{i}^{R}$ é o valor médio de itens alimentícios $i$ na região $R$, $q_{i}^{0}$ é a quantidade média de item alimentício $i$ na cesta, e $k$ é o fator de conversão. As unidades de valores $p_{i}^{R}$ são definidas como a despesa total reportada para um item específico dividida pela quantidade total comprada de cada item.

\subsection{Ajustando a linha de pobreza de custo de necessidades básicas de alimentos para o custo de necessidades básicas não alimentares}

Há uma série de fatores que impedem a aplicação da abordagem Custo de Necessidades Básicas (CBN) para determinação da linha de pobreza para os itens não alimentares. Por exemplo, para determinar a composição da cesta de alimentos para a linha de pobreza, pode-se usar a exigência de energia dos alimentos recomendada como uma base para definir o consumo de alimentos. Porém, é praticamente impossível elaborar um método semelhante para determinar os requisitos específicos de cada item não alimentar (como habitação, transporte, utilidades do lar, roupas e etc).

Para lidar com esse problema, este trabalho utiliza a metodologia proposta por Ravallion (1998) que propõe duas maneiras de estimar o ajuste para cima da linha de pobreza alimentar, levando em conta as necessidades básicas não alimentares. O primeiro método (Método A) baseia-se em famílias cujo total de dispêndio per capita é igual a linha de pobreza alimentar. Desde que as famílias com esse nível de gastos totais gastam algo em produtos não alimentícios, segue-se que eles estão dispostos a renunciar a algumas despesas de alimentos para satisfazer algumas das suas necessidades básicas não alimentares. Graficamente, o Segmento A na Figura 1 representa a provisão para as necessidades básicas não alimentares que deve ser adicionada à linha de pobreza alimentar. O Segmento A representa a quantidade de gastos que famílias com as despesas totais per capita igual a linha de pobreza de alimentos $\left(Z^{f}\right)$ renunciam a fim de comprar produtos básicos não alimentares.

O segundo método (Método B) se baseia nas famílias cujo dispêndio alimentar per capita é igual ao valor da linha de pobreza alimentar. Como a Figura 1 mostra, essas famílias acabam por gastar um montante adicional representado pelo segmento de linha B para itens não alimentares. Claramente, uma vez que o ajuste para despesas não alimentares básicas com o Método A é menor do que o ajuste com o Método B, a forma de ajuste A rende uma linha de pobreza mais baixa, enquanto a forma $B$ rende uma linha de pobreza superior. 
Linha de pobreza alimentar, $\mathrm{Z}^{f}$

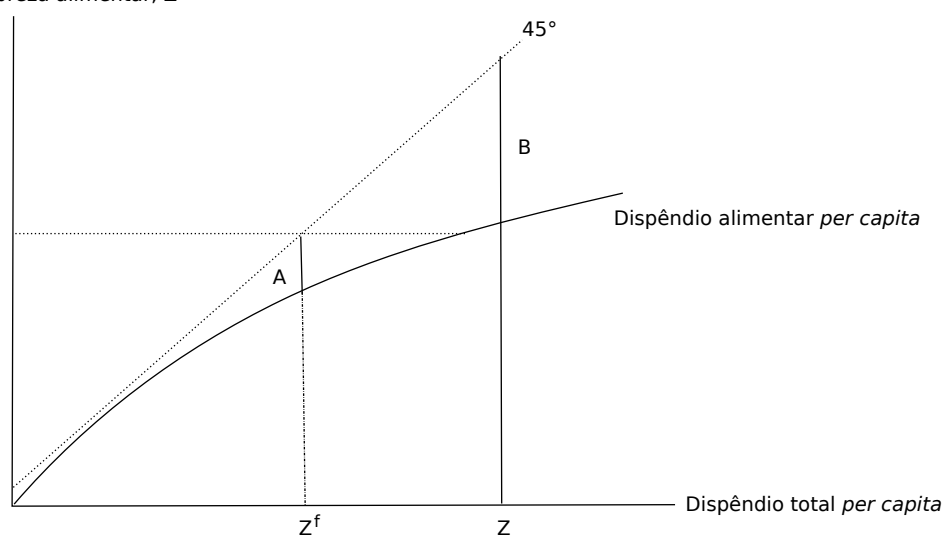

Source: Bank (2006)

Figura 1: O custo de necessidades básicas não alimentares

Seguindo Ravallion (1998), o ajustamento à linha de pobreza alimentar para produtos não alimentícios básicos pode ser realizado estimando-se uma curva de Engel, do tipo:

$$
w_{F}^{h}=\alpha_{0}+\sum_{j=1}^{n-1} \alpha_{j} R_{j}+\beta \ln \left(\frac{P C E^{h}}{F P L}\right)+\gamma X^{h}+\epsilon
$$

em que $w_{F}^{h}$, é a participação dos gastos com alimentação do domicílio $h, \alpha_{0}$ é um termo constante, $R_{j}$ é um conjunto de variáveis binárias para as cinco macrorregiões e para as áreas rurais e urbanas do Brasil como um todo, o PCE é a despesa total per capita, a FPL é a linha de pobreza alimentar, e $X^{h}$ denota as características dos domicílios como idade, sexo, anos de escolaridade do chefe e total de pessoas no domicílio.

$\mathrm{O}$ ajustamento mais baixo da linha de pobreza alimentar para produtos não alimentícios (Método A), para cada região, é obtido, primeiramente, por meio da estimação da participação alimentar das famílias com despesa total per capita próxima a linha de pobreza alimentar. Em outras palavras, pelo Método A determina a participação alimentar das famílias que possuem a despesa total per capita próxima a linha de pobreza alimentar. De posse da estimativa da participação de alimentos das famílias, a linha de pobreza mais baixa ${ }^{14}$ pode ser estimada como:

$$
P L^{R}(\text { baixa })=F P L^{R}+\left(1-w_{F}^{R}(\text { baixa })\right) \times F P L^{R}
$$

Dado que $P C E=F P L,\left(1-w_{F}^{R}\right) P C E=$ quantidade de gastos não alimentares na região $R$.

A linha de pobreza superior é baseada na estimativa da participação alimentar para a qual a despesa total em alimentos per capita é igual à linha de pobreza alimentar. Deixe $w_{F}^{R}$ (alta) denotar a participação dos alimentos na região $R$, estimada com base no Método B para ajustamento mais alto da linha de pobreza alimentar. Ou seja, a diferença no Método B é que a regressão é

\footnotetext{
${ }^{14}$ À cesta de pobreza mais baixa são dados vários nomes diferentes: cesta de subsistência mínima, cesta intermediária e linha de pobreza baixa.
} 
estimada com base nos domicílios que possuem o dispêndio total per capita com alimentos próximo à linha de pobreza alimentar. É importante destacar que, em termos de estimação, não é possível encontrar domicílios que possuam dispêndio total per capita (Método A) ou dispêndio alimentar total per capita (Método B) exatamente igual a linha de pobreza alimentar, sendo assim, procurou-se definir um intervalo ao redor da linha de pobreza alimentar, no qual encontra- se as famílias que farão parte de cada um dos modelos de ajustamento da linha de pobreza alimentar para produtos não alimentícios. Para definir esse intervalo seguiu-se o procedimento adotado por Ravallion (1998). A estimativa mais alta da linha de pobreza pode ser obtida como:

$$
w_{F}^{R}(\text { alta })=\hat{\alpha}^{R}+\hat{\beta} \ln \left(\frac{1}{w_{F}^{R}(\text { alta })}\right)=\hat{\alpha}^{R}+\hat{\beta} \ln \left(\frac{P C E^{h}}{F P L}\right)
$$

em que $\hat{\alpha}^{R}=\hat{\alpha_{0}}+\hat{\alpha_{j}} R_{j}+\hat{\gamma} \bar{X}^{h}$

Logo, tem-se:

$$
P L^{R}(\text { alta })=\frac{F P L^{R}}{w_{F}^{R}(\text { alta })}
$$

De forma resumida, as equações estimadas foram as seguintes. 1) Equações para cálculo da linha de pobreza mais baixa (Método A): calcula-se primeiro a participação alimentar das famílias com despesa total per capita próxima à linha de pobreza alimentar e, em seguida esse valor é usado na equação de cálculo da linha de pobreza mais baixa, que é a Equação (7). 2) Equações para cálculo da linha de pobreza mais alta (Método B): calcula-se primeiro participação alimentar das famílias com despesa total em alimentos per capita próxima à linha de pobreza alimentar e, em seguida esse valor é usado na equação de cálculo da linha de pobreza mais alta, Equação (9).

Definida a linha de pobreza, a questão seguinte é construir uma medidaresumo adequada do agregado de pobreza. No presente estudo, utiliza-se o índice Foster et al. (1984). Este indicador considera a proporção de pobres (incidência da pobreza), a distância (hiato) que estes estão da linha de pobreza (profundidade) e a desigualdade entre os mesmos (hiato quadrático), constituindo-se, assim, num indicador mais completo da pobreza. Na Seção 3, fornecem-se exemplos de como as novas linhas de pobreza impactam na medição de incidência da pobreza. Resultados para as demais medidas de pobreza estão disponíveis com os autores.

\subsection{Fonte de dados}

O trabalho utiliza como base de dados os microdados da Pesquisa de Orçamento Familiar (POF) realizada pelo IBGE. Essa pesquisa fornece informações sobre a composição do orçamento doméstico e visa, principalmente, mensurar as estruturas de consumo, dos gastos e dos rendimentos das famílias. Os dados utilizados neste trabalho são de dois pontos no tempo, POF de 2002-2003 (IBGE 2004) e POF de 2008-2009 (IBGE 2010). A POF 2002-2003 conta com 48.470 domicílios, já a POF 2008-2009 conta com 55.970 domicílios. 


\section{Novas linhas de pobreza para o Brasil}

$\mathrm{Na}$ Tabela 2, apresentam-se as diferentes linhas de pobreza alimentares estimadas segundo dados da POF 2002-2003, POF 2008-2009, e a metodologia descrita na Seção 2. A linha de pobreza de alimentos (linha de pobreza extrema) estimada para o Brasil é de $\mathrm{R} \$ 70,61$, com base nos dados da POF 2002 2003 e de $\mathrm{R} \$ 102,64$, com base nos dados da POF 2008-2009. O valor dessa mesma linha estimada para o Brasil pelo Bank (2006), também usando a POF 2002-2003, foi igual a $\mathrm{R} \$ 61$ per capita mensal ${ }^{15}$.

Com base nos resultados da Tabela 2, nota-se ainda que as linhas de pobreza de alimentos apresentam uma pequena variação de região para região, sugerindo diferenças não muito elevadas no custo de vida entre as regiões, conforme também foi destacado por Bank (2006) em 2003. O custo dos alimentos se mostrou mais elevado na região Centro-Oeste do Brasil com base nos dados da POF 2002-2003 e na região Norte, com base na POF de 20082009. A região Sul, por outro lado, apresentou a menor linha de pobreza de alimentos do Brasil nos dois anos analisados. Em ambas as pesquisas, as áreas rurais do Brasil apresentaram um valor da cesta de necessidades básicas alimentares menor que nas áreas urbanas.

Tabela 2: Linha de pobreza de alimentos per capita mensal para POF 2002-2003 e para POF 2008-2009

\begin{tabular}{lccc}
\hline \multirow{2}{*}{ Região } & \multicolumn{3}{c}{ Linha de Pobreza de Alimentos (Extrema Pobreza) } \\
\cline { 2 - 4 } & POF 2002-2003 & $\begin{array}{c}\text { POF 2002-2003 } \\
\text { Inflacionado para jan-2009 }\end{array}$ & POF 2008-2009 \\
\hline Brasil & 70,61 & 100,03 & 102,64 \\
Brasil Rural & 67,47 & 95,58 & 100,59 \\
Brasil Urbano & 71,60 & 101,43 & 103,03 \\
Sudeste & 72,77 & 103,09 & 105,46 \\
Nordeste & 72,37 & 102,52 & 102,98 \\
Norte & 71,82 & 101,75 & 113,26 \\
Sul & 67,20 & 95,20 & 100,34 \\
Centro-Oeste & 74,98 & 106,22 & 104,44 \\
\hline Fonte: Dados da pesquisa. & & \\
Nota: Linhas de pobreza são expressas em R\$, de janeiro de 2003 e de janeiro de \\
2009.
\end{tabular}

Comparando-se as linhas de pobreza calculadas com base na POF 20022003 corrigidas para janeiro de 2009 com as linhas de pobreza calculadas com base na POF 2008-2009, nota-se que essas últimas apresentam valores um pouco mais elevados do que as primeiras. Esta diferença reflete a mudança no padrão de consumo que tem ocorrido no Brasil nas últimas décadas e mudanças nos preços relativos dos produtos na cesta.

\footnotetext{
${ }^{15}$ A diferença entre o valor da linha de pobreza de alimentos calculado no presente estudo $(\mathrm{R} \$ 70,61)$ e o valor calculado pelo World Bank $(\mathrm{R} \$ 61,00)$ pode ser explicada, primeiramente, devido ao uso de tabelas nutricionais diferentes para calcular o valor calórico dos 26 tipos de alimentos incluídos na cesta de necessidades básicas. No presente estudo, utilizou-se a Tabela Brasileira de Composição de Alimentos (TACO) e a tabela da Dra. Sônia Tucunduva (Philippi 2002). Além do uso de tabelas nutricionais diferentes, cabe lembrar que podem surgir diferenças nos resultados devido às diferenças na forma de agregação dos produtos, relacionadas as diferentes decisões tomadas quanto à inclusão dos subitens no agregado de cada item alimentício. Para se proceder ao agrupamento dos itens alimentícios seguiu-se as categorias descritas pelo IBGE (2004).
} 
Nas Tabelas 2 e 3, encontram-se as estimativas para as linhas de pobreza baixas e linhas de pobreza altas para o Brasil, para as áreas rurais e urbanas e para as macrorregiões do Brasil, segundo as duas pesquisas ${ }^{16}$. Analisandose, primeiramente, os resultados da POF 2002-2003, verifica-se que o valor da linha de pobreza baixa encontrado para o Brasil é de $\mathrm{R} \$ 114,58$, per capita mensal. Este valor está próximo aos valores que foram calculados por outras referências, como por exemplo: a linha de miséria de $\mathrm{R} \$ 108,00$, calculada pelo Centro de Política Social da Fundação Getúlio Vargas (FGV); e a linha de pobreza baixa calculada para o Brasil pelo Bank (2006), a qual apresentou valor médio de $\mathrm{R} \$ 103,00$ per capita por mês, e também a linha de pobreza administrativa estabelecida para o Brasil em 2003, usada pelo programa Bolsa Família, de $\mathrm{R} \$ 100$ por pessoa por mês.

Tabela 3: Linhas de pobreza para o Brasil baseado no método CBN ajustado para itens não alimentares, POF 2002-2003, em R\$, por pessoa e por mês

\begin{tabular}{lcccc}
\hline & \multicolumn{2}{c}{ Linha de Pobreza Baixa } & \multicolumn{2}{c}{ Linha de Pobreza Alta } \\
\cline { 2 - 5 } & POF 2002-2003 & $\begin{array}{r}\text { POF 2002-2003 } \\
\text { Corrigida para } \\
\text { jan 2009 }\end{array}$ & $\begin{array}{r}\text { POF 2002-2003 } \\
\text { POF 2002-2003 } \\
\text { Corrigido para } \\
\text { jan 2009 }\end{array}$ \\
\hline Brasil & 114,58 & 162,32 & 213,89 & 303,01 \\
Brasil Rural & 109,47 & 155,09 & 204,35 & 289,50 \\
Brasil Urbano & 116,17 & 164,59 & 216,86 & 307,22 \\
Sudeste & 118,08 & 167,28 & 220,43 & 312,28 \\
Nordeste & 117,42 & 166,35 & 219,19 & 310,53 \\
Norte & 116,52 & 165,07 & 217,52 & 308,16 \\
Sul & 109,03 & 154,46 & 203,53 & 288,34 \\
Centro-Oeste & 121,65 & 172,34 & 227,09 & 321,72 \\
\hline
\end{tabular}

Fonte: Dados da pesquisa.

Da mesma forma que ocorreu com a linha de pobreza de alimentos, a linha de pobreza baixa não varia muito entre as regiões, sendo o menor valor dessa linha encontrado na região Sul e o valor mais alto encontrado na região CentroOeste. Novamente, as áreas rurais apresentam valores menores que nas áreas urbanas.

A linha de pobreza alta do método CBN estabelece um limite de linhas de pobreza mais generoso. Em contraste com a linha de pobreza baixa, o ajustamento para o custo das necessidades básicas para itens não alimentícios agora é determinado pelos domicílios que possuem dispêndio alimentar per capita igual ao valor da linha de pobreza alimentar. Por meio da Tabela 4, encontra-se o valor da linha de pobreza alta para o Brasil, que é de $\mathrm{R} \$ 213,89$, com base nos dados da POF 2002-2003. Nota-se que esse valor é quase duas vezes maior que o da linha de pobreza baixa.

$\mathrm{Na}$ Tabela 4, são apresentadas as linhas de pobreza baixa e alta, calculadas com base na POF 2008-2009. A linha de pobreza baixa estimada para o Brasil é de $\mathrm{R} \$ 166,54$. Comparando-se esse resultado ao valor apresentado

\footnotetext{
${ }^{16}$ As linhas de pobreza sem imputação são um pouco maiores do que as linhas com imputação. Isso se deve à forma da equação de cálculo da linha de pobreza (Equação (7) e (8)). Ao realizar a imputação essa parcela se torna maior e consequentemente a linha menor. Sendo assim, as linhas são menores após a imputação. Para as linhas mais baixas os valores são em torno de 1,4\% menores. Já para as linhas mais altas os valores calculados são aproximadamente $4,1 \%$ menores do que as linhas sem imputação.
} 
em 2003, corrigido para janeiro de 2009 ( $\mathrm{R} \$ 162,32$ ), percebe-se que houve uma pequena valorização. Ou seja, ao se retirar o efeito médio dos preços, comparando-se as duas linhas em 2009, a linha calculada com base na estrutura de dados de 2009 é maior. Portanto, percebe-se que aumentaram os gastos das famílias em necessidades básicas alimentares e não alimentares.

Da mesma forma que ocorreu com a linha de pobreza de alimentos e a linha de pobreza baixa de 2002-2003, não há grandes variações nos valores da linha de pobreza baixa de 2008-2009 entre as regiões, sendo o menor valor da linha de pobreza encontrado na região Sul e o valor mais alto encontrado na região Norte, com uma diferença de 12,9\%. Assim como em 2002-2003, a linha de pobreza das áreas urbanas é maior que das áreas rurais.

Tabela 4: Linhas de pobreza para o Brasil baseado no método CBN ajustado para itens não alimentares, POF 20082009, em R\$, por pessoa e por mês

\begin{tabular}{lcc}
\hline & Linha de Pobreza Baixa & Linha de Pobreza Alta \\
\hline Brasil & 166,54 & 308,41 \\
Brasil Rural & 163,21 & 302,24 \\
Brasil Urbano & 167,16 & 309,56 \\
Sudeste & 171,11 & 316,87 \\
Nordeste & 167,09 & 309,42 \\
Norte & 183,77 & 340,31 \\
Sul & 162,81 & 301,49 \\
Centro-Oeste & 169,46 & 313,80 \\
\hline
\end{tabular}

Fonte: Dados da pesquisa.

Nota: Linhas de pobreza são expressas em R\$, janeiro de 2009.

O valor da linha de pobreza alta para o Brasil em 2008-2009 foi de $\mathrm{R} \$ 308,41$. Esse valor é quase duas vezes o valor da linha de pobreza baixa (R $\$ 166,54)$. Em comparação aos resultados encontrados para a POF 2002-2003, percebe-se também que houve alteração no padrão de consumo, já que o valor calculado para 2002-2003, corrigido para $R \$$ de janeiro de 2009 , foi de apenas $R \$ 303,01$ (Tabela 3). Os valores das linhas regionais apresentam comportamentos semelhantes aos das linhas baixas.

É importante destacar que o fato de a despesa total per capita do grupo de referência ter aumentado mais do que a linha de pobreza alimentar reflete o fato de os gastos com alimentos terem aumentado mais lentamente do que os gastos com outros itens. Isso fornece uma âncora para todas as outras linhas de pobreza. O fato de que a linha de pobreza alimentar não mudou em grande quantidade significa que agora, espera-se um ajuste maior para os itens não alimentares, que é o que de fato ocorre. Mas a magnitude do ajuste para itens não alimentares não é linear (refletindo a curva de Engel na Figura 1). Não é apenas o aumento observado no gasto total. $\mathrm{O}$ ajuste depende dos coeficientes estimados na Equação (6). Não é uma relação de um para um com o aumento da despesa total.

Além disso, é importane também ressaltar que os valores estimados no presente estudo têm menos variação entre as regiões do que as linhas que foram estimadas por Rocha (2000). Algumas diferenças nos procedimentos metodológicos adotados no presente estudo em comparação aos que foram adotados por Rocha (2000) conduziram a essa diferenciação nas linhas estimadas, fazendo com que as linhas calculadas no presente estudo se tornassem mais ho- 
mogêneas, sem grandes variações espaciais. Rocha (2000) definiu uma cesta de bens diferente em cada região. Além disso, Rocha (2000) usa POF de 19871988, a qual tinha somente informações sobre áreas metropolitanas. Por fim, para estimar as linhas de pobreza nas zonas rurais, Rocha utiliza informações do ENDEF dos anos 70 sobre os custos relativos nas áreas urbanas e rurais em cada região abrangida pelo ENDEF.

O fato de Rocha (2000) utilizar cestas que variam por região, introduz uma variação em suas linhas de pobreza em função das espeficidades de consumo regional. No presente estudo, a utilização de uma metodologia com uma única cesta de consumo para o país permite comparações mais consistentes.

Todos os estudos que utilizaram POF 1987-1988 ou POF 1995-1996 apenas tiveram informações sobre áreas metropolitanas. Assim, foram forçados a contar com o ENDEF ou outras estimativas para derivar linhas de pobreza para as áreas rurais. No presente estudo, não foi necessário adotar esse procedimento, porque POF 2002 e 2008 têm cobertura nacional. Por fim, é importante destacar também que é provável que, devido à melhoria das redes de transporte no Brasil, tenha havido uma convergência dos padrões de consumo e dos preços relativos entre as regiões do país. Assim, a divergência regional nos preços metropolitanos é, provavelmente, menor na década de 2000 do que na década de 1980, e a variabilidade regional nos preços rurais é, quase certamente, menor hoje do que a observada com a ENDEF nos anos 70.

Nesse sentido é importante mencionar que Hoffmann (1998), em seu estudo, também tenta explicar por que as linhas de pobreza usadas por Rocha (1993) são muito diferentes entre áreas urbanas e rurais.

O ajustamento promovido nas linhas de pobreza de alimentos para considerar os itens não alimentícios é importante para permitir a inclusão desses itens na cesta de pobreza, ou seja, permite que as famílias tenham acesso não somente aos itens alimentícios, mas também aos itens não alimentícios de necessidades básicas, seja pela linha de pobreza baixa ou pela linha de pobreza alta. Esse ajustamento terá impactos significativos sobre as taxas de pobreza, já que a linha de pobreza baixa é quase duas vezes maior que a linha de extrema pobreza e a linha alta, por sua vez, é quase duas vezes maior que a linha baixa. Além disso, as mudanças ocorridas nas linhas de pobreza de 2002-2003 para 2008-2009 terão um impacto pequeno nos cálculos dos índices de pobreza e, consequentemente, no perfil de pobreza definido para o Brasil, conforme será visto adiante.

\subsection{Uma discussão sobre a adequação das novas linhas estimadas no contexto do Brasil}

Em publicação do Bank (2006), concluiu-se que a linha de extrema pobreza e a linha de pobreza baixa são as mais relevantes para políticas. Essa escolha foi baseada em duas razões: a primeira é que estas duas linhas de pobreza são limites de pobreza mais úteis para identificar os domicílios com necessidades mais urgentes. A linha de extrema pobreza é relevante para identificar domicílios que não podem nem mesmo satisfazer as necessidades básicas de alimentos, enquanto a linha de pobreza baixa é util para identificar indivíduos que não podem satisfazer necessidades básicas totais com itens alimentícios e não alimentícios (sendo essas últimas estimadas de uma forma conservadora). A segunda razão é baseada em considerações mais práticas. Ambas as linhas de pobreza estão próximas às linhas de pobreza administrativas definidas para 
o Brasil, de R\$50 e R\$100 em 2003 per capita por mês, as quais eram usadas para elegilibilidade do programa Bolsa Família.

Mas por que não rever os valores dessas linhas de pobreza que vêm sendo amplamente utilizadas no Brasil com base em argumentos teóricos e empíricos? A consideração de uma terceira linha de pobreza, mais elevada, também estimada por meio de um método claro e consistente, que considera integralmente as necessidades básicas alimentares e não alimentares, pode ser de grande relevância para a identificação das famílias pobres e para o desenho de políticas públicas de enfrentamento da pobreza. Por isso, uma análise cuidadosa acerca dessa questão se faz necessária.

As duas linhas administrativas do governo em 2009 - de R $\$ 70$ para extrema pobreza e de $\mathrm{R} \$ 140$ para pobreza - eram mais baixas que as linhas calculadas no presente estudo: $\mathrm{R} \$ 102,64$ para alimentos e $\mathrm{R} \$ 166,54$ para a linha de pobreza baixa. Entretanto, vale a pena lembrar que a linha de pobreza baixa fornece um limite inferior da quantidade de dinheiro necessário para cobrir as necessidades básicas alimentares e não alimentares. Somente porque a linha de pobreza mais baixa é mais próxima das linhas administrativas não significa que é a linha mais adequada. O argumento para consideração da linha de pobreza mais alta surge da percepção de que, no caso dessa linha, o ajustamento para considerar o custo das necessidades básicas com itens não alimentícios é baseado na estimativa da participação alimentar para os domić́lios nos quais a despesa total em alimentos per capita é igual à linha de pobreza alimentar. Sendo assim, a linha é definida por meio do dispêndio dos domicílios que são capazes de satisfazer as necessidades básicas em alimentos. Já no caso da linha de pobreza baixa, o ajustamento é definido pelos domicílios para os quais o total de dispêndio per capita é igual ao valor da linha de pobreza alimentar. Por esse motivo, a linha superior é tão apropriada como a linha inferior, e ainda mais defensável. Na análise empírica abaixo, utilizam-se as duas linhas por duas razões. Em primeiro lugar, elas fornecem um limite inferior e superior de onde a linha de pobreza verdadeira deveria se localizar. Em segundo lugar, eles nos permitem distinguir três grupos que provavelmente têm necessidades diferentes: os "extremamente pobres", "o grupo baixo de pobres" e "o grupo alto de pobres". Somente quando as famílias têm renda acima da linha de pobreza alta podemos estar certos de que têm renda suficiente para cobrir as duas necessidades, alimentares e não alimentares.

Nesse sentido, Birdsall et al. (2014) apresentam argumentos de que há necessidade de se levar em consideração, na América Latina, um grupo que os autores chamam de "grupo vunerável", que não é pobre pelos padrões internacionais de US\$1,25 e US\$2,00 por dia, mas ainda não fazem parte da classe média que tem uma renda mais segura e uma probabilidade muito menor de cair na pobreza quando sofrer um choque macroeconômico ou idiosincrático. Segundo os autores, essas pessoas vivem em domicílios que possuem renda per capita diária entre US $\$ 4,00$ e US\$10,00 dólares PPC (Poder de Paridade de Compra) ${ }^{17}$.

O presente estudo está de acordo com a análise de Birdsall et al. (2014) sobre a importância da identificação de um grupo de transição que já não é pobre, por estar acima da linha de pobreza, mas que ainda tem de consolidar a sua posição na classe média. No entanto, discorda-se que a renda desse grupo caia na faixa de US\$ 4,00 a US\$10,00 dólares PPC. Considerando o

${ }^{17}$ Os autores usam dólares PPC de 2005. 
ajustamento do poder de paridade de compra para 2009, tem-se uma taxa de câmbio média de $1,71 \mathrm{R} \$ / \mathrm{US} \$$ (www.ipeadata.gov.br) ${ }^{18}$. Com essa taxa de câmbio, as três linhas de pobreza estimadas no presente estudo traduzem-se para cerca de 2,00, 3,25 e 6,00 dólares per capita, por dia. Assim, identifica-se como pobre uma parcela considerável das famílias que Birdsall et al. (2014) chamam de vulnerável. Sendo assim, sugere-se que um limite mais apropriado para as famílias "próximas de pobres" ou "vulneráveis" deve começar em torno de US\$ 6,00.

Tanto para os pobres, como os "próximos de pobre", é importante incorporar na análise a questão da vulnerabilidade. Esse tipo de análise é fundamental em estudos de pobreza, pois leva em consideração a insegurança das famílias e a possibilidade de perder o pouco que se tem. Esta discussão se torna de fundamental importância, em um país com as características do Brasil, em que a renda dos pobres está sujeita a muitas oscilações. O aumento das taxas inflacionárias tende afetar de forma mais severa a população de baixa renda, as quais não possuem mecanismos de proteção contra a corrosão inflacionária, some-se a isso o fato de que a população de baixa renda tem maior parte de sua renda comprometida com itens essenciais à sua sobrevivência. Cabe destacar ainda, a grande informalidade no mercado de trabalho que está fortemente associada à pobreza no Brasil, já que no mercado informal não há acesso à seguro desemprego e outros mecanismos que poderiam suavizar choques de renda, contribuindo para deixar essas famílias ainda mais vulneráveis. Assim, a manutenção das famílias fora da pobreza se torna uma questão quase tão importante quanto a retirada das mesmas dessa condição.

Dessa forma, com base em argumentos teóricos e empíricos, tem-se razões para acreditar que as linhas de pobreza de alimentos e a linha de pobreza baixa são realmente muito baixas, e são ainda mais baixas as linhas de pobreza administrativas do governo. Portanto, o governo ao utilizar essas linhas para elegibilidade de programas sociais pode estar deixando de atender à uma importante parcela da população que precisa de auxílio, e outra parcela da população que precisa de mecanismos de proteção para lidar com situações de risco e vulnerabilidade.

\section{A pobreza extrema, baixa e alta no Brasil segundo as novas linhas}

Com base nas três linhas de pobreza estimadas, e ainda nas duas linhas de pobreza administrativas adotadas para elegibilidade do Programa Bolsa Família, pode-se quantificar as diferenças nas taxas de pobreza considerando cada uma destas linhas. Na Tabela 5 apresenta-se o perfil da pobreza, com base no índice de incidência da pobreza (P0), que é equivalente ao percentual da população que está abaixo da linha da pobreza no Brasil, em cada uma das macrorregiões e nas áreas rurais e urbanas do país, de acordo com dados mais recentes da Pesquisa de Orçamento Familiar, POF 2008-200919.

Na primeira linha da Tabela 5, apresentam-se os índices calculados com base na linha de pobreza de 2003 corrigida para 2009, utilizando os dados

\footnotetext{
${ }^{18}$ Esse cálculo é baseado em dólares PPC de 2005 ajustados para 2009, com base nas taxas relativas de inflação no Brasil e os EUA.

${ }^{19}$ Para fins de exemplificação, apresentam-se apenas os resultados dos índices de pobreza de 2009 , que são mais recentes.
} 
Tabela 5: Proporção de pobres para o Brasil, macrorregiões, áreas rurais e áreas urbanas e os respectivos valores das linhas de pobreza utilizada em seu cálculo - POF 2008-2009

\begin{tabular}{|c|c|c|c|c|c|}
\hline & \multicolumn{5}{|c|}{ Índice de Pobreza (PO) - POF 2008-2009 } \\
\hline & \multicolumn{5}{|c|}{$\begin{array}{c}\text { LP Extrema LP Baixa LP Alta } \begin{array}{l}\text { LP Extrema } \\
\text { Bolsa Fam. }\end{array} \text { PP Bolsa Família }\end{array}$} \\
\hline $\begin{array}{l}\text { Brasil: linhas de } \\
\text { 2002-2003 corrigida } \\
\text { para } 2009\end{array}$ & $\begin{array}{c}5,17 \\
R \$ 100,05\end{array}$ & $\begin{array}{c}14,09 \\
R \$ 162,32\end{array}$ & $\begin{array}{c}35,48 \\
R \$ 303,01\end{array}$ & $\begin{array}{c}2,14 \\
R \$ 70,00\end{array}$ & $\begin{array}{c}10,67 \\
R \$ 140,00\end{array}$ \\
\hline Brasil & $\begin{array}{c}5,46 \\
R \$ 102,64\end{array}$ & $\begin{array}{c}14,74 \\
R \$ 166,54\end{array}$ & $\begin{array}{c}36,19 \\
R \$ 308,41\end{array}$ & $\begin{array}{c}2,14 \\
R \$ 70,00\end{array}$ & $\begin{array}{c}10,67 \\
R \$ 140,00\end{array}$ \\
\hline Brasil Rural & $\begin{array}{c}14,28 \\
R \$ 100,59\end{array}$ & $\begin{array}{c}31,62 \\
R \$ 163,21\end{array}$ & $\begin{array}{c}59,98 \\
R \$ 302,24\end{array}$ & $\begin{array}{c}6,39 \\
R \$ 70,00\end{array}$ & $\begin{array}{c}25,26 \\
R \$ 140,00\end{array}$ \\
\hline Brasil Urbano & $\begin{array}{l}3,76 \\
R \$ 103,03\end{array}$ & $\begin{array}{c}11,52 \\
R \$ 167,16\end{array}$ & $\begin{array}{c}31,77 \\
R \$ 309,56\end{array}$ & $\begin{array}{c}1,35 \\
R \$ 70,00\end{array}$ & $\begin{array}{c}7,95 \\
R \$ 140,00\end{array}$ \\
\hline Sudeste & $\begin{array}{c}2,57 \\
R \$ 105,46\end{array}$ & $\begin{array}{c}8,31 \\
R \$ 171,11\end{array}$ & $\begin{array}{c}26,36 \\
R \$ 316,87\end{array}$ & $\begin{array}{c}0,81 \\
R \$ 70,00\end{array}$ & $\begin{array}{c}5,28 \\
R \$ 140,00\end{array}$ \\
\hline Sul & $\begin{array}{c}1,37 \\
R \$ 100,34\end{array}$ & $\begin{array}{c}5,90 \\
R \$ 162,81\end{array}$ & $\begin{array}{c}21,82 \\
R \$ 301,49\end{array}$ & $\begin{array}{c}0,40 \\
R \$ 70,00\end{array}$ & $\begin{array}{c}3,78 \\
R \$ 140,00\end{array}$ \\
\hline Norte & $\begin{array}{c}9,32 \\
R \$ 113,26\end{array}$ & $\begin{array}{c}24,17 \\
R \$ 183,77\end{array}$ & $\begin{array}{c}53,86 \\
R \$ 340,31\end{array}$ & $\begin{array}{c}2,82 \\
R \$ 70,00\end{array}$ & $\begin{array}{c}14,75 \\
R \$ 140,00\end{array}$ \\
\hline Nordeste & $\begin{array}{c}12,80 \\
R \$ 102,98\end{array}$ & $\begin{array}{c}30,56 \\
R \$ 167,90\end{array}$ & $\begin{array}{c}59,42 \\
R \$ 309,42\end{array}$ & $\begin{array}{c}5,46 \\
R \$ 70,00\end{array}$ & $\begin{array}{c}23,12 \\
R \$ 140,00\end{array}$ \\
\hline Centro-Oeste & $\begin{array}{c}4,38 \\
R \$ 104,44\end{array}$ & $\begin{array}{c}12,96 \\
R \$ 169,46\end{array}$ & $\begin{array}{c}36,82 \\
R \$ 313,81\end{array}$ & $\begin{array}{c}1,36 \\
R \$ 70,00\end{array}$ & $\begin{array}{c}9,09 \\
R \$ 140,00\end{array}$ \\
\hline
\end{tabular}

Fonte: Dados da pesquisa.

de consumo da POF 2008-2009 como base da medida de bem-estar para o Brasil. Já no restante da tabela, apresentam-se os índices calculados com base nas linhas de pobreza de 2009 e estrutura de dados da POF 2008-2009. Podese constatar que a incidência da pobreza no Brasil, considerando-se a linha de extrema pobreza de 2003 corrigida para 2009, foi de 5,17\%, um pouco menor que a incidência calculada com base na linha de 2008-2009, de acordo com a qual $5,46 \%$ dos domicílios brasileiros não possuem dispêndio total em consumo suficiente para satisfazer as necessidades básicas de alimentos. Os resultados mostram que, embora as linhas de pobreza difiram um pouco, a incidência da pobreza não é muito sensível para a escolha do ano usado para construir a linha de pobreza (2002-2003 vs. 2008-2009). A diferença entre os dois índices calculados reflete as mudanças no padrão de consumo.

Analisando-se as taxas regionais de extrema pobreza, nota-se que as regiões Norte e Nordeste tiveram as maiores taxas de pobreza entre todas as regiões. As regiões Sul e Sudeste tiveram as menores taxas e a região CentroOeste aparece em posição intermediária. Considerando-se apenas áreas urbanas e rurais nota-se que a pobreza extrema rural é quase quatro vezes maior que a pobreza extrema urbana. Diante dessas observações, cabe destacar a necessidade de utilizar diferentes instrumentos de políticas para reduzir a pobreza entre diferentes regiões e localizações.

Nota-se que os índices de pobreza aumentam substancialmente quando as despesas básicas não alimentares estão incorporadas nas linhas de pobreza. $\mathrm{O}$ ajuste da linha de pobreza alimentar para as necessidades básicas não alimentares faz uma grande diferença na taxa de pobreza estimada. Para o Brasil percebe-se que o índice de pobreza aumenta de 5,46\%, considerando a linha de extrema pobreza, para $14,74 \%$, considerando a linha de pobreza baixa e para $36,19 \%$, considerando a linha de pobreza alta. Dada a incerteza sobre 
onde a linha de pobreza verdadeira reside, os resultados ressaltam a importância da inclusão da linha de pobreza superior na análise. Nesse caso, 21,4\% da população se encontra acima da linha de pobreza baixa e abaixo da linha de pobreza alta. São necessárias mais pesquisas sobre a dinâmica deste grupo. Recessões e choques idiossincráticos poderiam conduzir uma parte deste grupo de volta à pobreza extrema ou pobreza baixa. Um mercado de trabalho robusto juntamente com o aumento do capital humano, por outro lado, poderia ajudar parte deste grupo a sair da pobreza e juntar-se aos "próximos de pobres" ou até mesmo à classe média.

Destaca-se também uma divergência grande entre os números apresentados acima e a incidência da pobreza no Brasil estimada com base nas linhas de pobreza administrativas adotadas para elegibilidade do Programa Bolsa Família. Como as linhas administrativas são mais baixas, a proporção de pobres também é significativamente menor, conforme pode ser constatado na Tabela 5. A taxa de pobreza para o Brasil é de apenas $2,14 \%$ usando-se a linha de extrema pobreza do governo, de $\mathrm{R} \$ 70,00$, e de $10,67 \%$ usando-se a linha de pobreza de $\mathrm{R} \$ 140,00$.

Portanto, tiram-se duas conclusões importantes dessas análises. Primeiro, que o número de famílias pobres focalizadas pelos programas do governo é menor do que seria caso este número fosse calculado com base nas linhas de pobreza extrema e linha de pobreza baixa. Para melhor compreensão deste resultado, podem-se analisar alguns números sobre quantos domicílios deixam de ser cobertos pelo programa devido à diferença de resultado entre estas linhas. O percentual de domicílios que deixa de ser coberto devido à diferença entre as linhas de $\mathrm{R} \$ 70,00$ e de $\mathrm{R} \$ 102,00$ (linhas de extrema pobreza) é de $3,32 \%$, o que representa 1.945 .520 famílias que necessitam de auxílio, mas não têm acesso ao programa ${ }^{20}$. Já o percentual de famílias que não são cobertas devido à diferença entre as linhas de $\mathrm{R} \$ 140,00$ e de $\mathrm{R} \$ 166,00$ (linhas de pobreza baixa) é de $4,07 \%$, que representa 2.385 .020 famílias sem acesso ao programa. A segunda conclusão é de que existe um percentual da população considerável no grupo de pobreza alta (21,39\%), em torno de 12.534 .540 de famílias, e esse grupo também não tem sido incluído nas políticas sociais.

No entanto, deve ressaltar que a consideração dessas linhas de pobreza mais altas, implicaria em grande impacto no orçamento público destinado as políticas sociais de enfrentamento da pobreza. Em nível de ilustração, em 2009 , ao se considerar o percentual de população que não tem sido considerado elegível às políticas sociais que é de $21 \%$, tem-se que, conforme apontado anteriormente, 12.534 .540 de famílias a mais deveriam estar sendo atendidas pelo programa Bolsa Família, se fosse considerado a linha de pobreza mais alta. Esses resultados são importantes em termos de políticas públicas, já que ressaltam a necessidade de consideração de novas linhas de pobreza no Brasil que possam refletir a real situação da população e propiciar o atendimento de suas necessidades mais básicas, permitindo assim um melhor direcionamento das políticas sociais de enfrentamento da pobreza. Destaca-se ainda que seria necessário o direcionamento de uma parcela maior do orçamento público para enfrentamento da pobreza no Brasil, associada não somente às transferências de renda, mas a políticas especificas que ajudem a população no grupo alto dos pobres, além do grupo vulnerável que são os "próximos aos pobres", a

\footnotetext{
${ }^{20}$ Esse percentual foi calculado com base no levantamento divulgado pelo IBGE (PNAD 2009) de 58,6 milhões de domicílios existentes no Brasil.
} 
lidar com riscos e a evitar que caiam abaixo da linha de pobreza baixa ou alta. Também são necessárias medidas que permitam o desenvolvimento social de toda a população pobre para que estas famílias deixem de depender de ajuda governamental e passem a ser capazes de gerar a sua própria renda de forma sustentável.

\section{Conclusões}

Considerando os objetivos descritos neste trabalho, estimaram-se as linhas de extrema pobreza (de alimentos) e linhas de pobreza ajustadas para itens não alimentícios (linhas de pobreza baixa e alta), com base nos dados de consumo das POFs 2002-2003 e 2008-2009. Além disto, apresentou-se a metodologia para construção do agregado de consumo, com imputação para correção de erros de mensuração no consumo alimentar e imputação do fluxo de bens duráveis da POF.

As linhas de extrema pobreza e as linhas ajustadas para considerar itens não alimentícios (baixa e alta) estimadas no presente estudo são maiores que as linhas administrativas respectivas do governo, o que se reflete em taxas de pobreza mais elevadas. Dessa forma, apresentam-se alguns argumentos teóricos e empíricos para a necessidade de consideração de novas linhas de pobreza para o Brasil. A consideração desta nova família de linhas de pobreza, estimada por meio de um método claro e consistente, poderá ter grande impacto sobre os números de pobreza, no orçamento público destinado as políticas sociais de enfrentamento da pobreza e no desenho de diferentes tipos de políticas para subgrupos da população pobre.

Nesse sentido, o governo ao adotar as linhas administrativas para elegibilidade aos programas sociais pode estar deixando de atender à uma importante parcela da população que precisa de auxílio. Essa constatação fica clara ao se estimar as taxas de pobreza considerando as diferentes linhas de pobreza. Em 2009, a proporção de pobres com base na linha de extrema pobreza e pobreza baixa foi de $5,46 \%$ e $14,74 \%$, respectivamente. Ao se considerar a linha de pobreza mais alta a proporção de pobres no Brasil fica em $36,19 \%$ da população. Em contraposição, de acordo com as linhas administrativas, as taxas de pobreza são substancialmente mais baixas, de $2,14 \%$ considerando a linha de extrema pobreza e 10,67\% considerando a linha de pobreza.

Ainda a partir das estimativas das novas linhas de pobreza, fica evidente um percentual considerável da população que não tem sido considerado elegível às políticas sociais, pois consegue ultrapassar a linha de pobreza baixa, porém está abaixo da linha de pobreza alta e pode facilmente retornar à condição de pobreza extrema ou baixa. Esse grupo é representado por mais de $21 \%$ da população em 2009, sendo maior do que os outros dois grupos juntos, o grupo dos que vivem em extrema pobreza (5,46\% da população) e o grupo dos que tem renda que ultrapassa a linha de extrema pobreza, mas que fica abaixo da linha de pobreza baixa $(9,28 \%)$.

Esse tipo de análise diferenciada é fundamental em estudos de pobreza, pois leva em consideração a insegurança das famílias e a possibilidade de perder o pouco que se tem. Em um país como o Brasil, em que a renda dos mais pobres está sujeita à muitas oscilações, a manutenção das famílias fora das situações mais severas de pobreza se torna uma questão tão importante quanto a retirada inicial dessa condição. É importante destacar também que os re- 
sultados alcançados nesse tipo de análise permitem evidenciar como os níveis de pobreza estão diretamente ligados às medidas e procedimentos adotados, sendo necessário, portanto, um contínuo aperfeiçoamento dos mesmos.

\section{Referências Bibliográficas}

Bank (2006), Brazil: measuring poverty using household consumption, Technical report, World Bank. Document of the World Bank, Report n. 36358-BR.

Barros, R. P., Henriques, R. \& Mendonça, R. (2000), A estabilidade inaceitável: desigualdade e pobreza no Brasil, in R. Henriques, ed., 'Desigualdade e Pobreza no Brasil', IPEA, Rio de Janeiro, pp. 21-48.

Birdsall, N., Lustig, N. \& Meyer, C. (2014), World Development, Vol. 60. 132146.

CEPAL (2002), Meeting the millennium poverty reduction targets in Latin America and the Caribbean, ECLAC, Santiago, Chile.

Chen, S. \& Ravallion, M. (2008), The developing world is poorer than we thought, but no less successful in the fight against poverty. Policy Research Working Paper 4703, The World Bank Development Research Group.

Corrêa, A. J. (1998), Distribuição de renda e pobreza na agricultura brasileira, Piracicaba, SP.

Crespo, A. P. \& Gurovitz, E. (2002), 'A pobreza como fenômeno multidimensional', RAE-Eletrônica 1(1).

Deaton, A. (1997), 'The analysis of household surveys: a microeconometric approach to development policy', Johns Hopkins University Press .

Deaton, A. \& Zaidi, S. (2002), Guidelines for constructing consumption aggregates for welfare analysis. n. 135 in Living Standards Measurement Study Working Paper, The World Bank, Washington, DC.

Fields, G. S. (2001), Distribution and development: a new look at the developing world, Russell Sage Foundation, New York.

Figueiredo, F. M. R., Helfand, S. M. \& Levine, E. S. (2007), Income versus consumption measures of rural poverty and inequality in Brazil. Working Paper, University of California, Riverside.

Foster, J., Greer, J. \& Thorbecke, E. (1984), 'A class of decomposable poverty measures', Econometrica 52, 761-776.

Hoffmann, R. (1998), 'Pobreza e desnutrição de crianças no Brasil', Economia Aplicada 2(2), 299-315.

Hoffmann, R. (2000), Mensuração da desigualdade e da pobreza no Brasil, in R. Henriques, ed., 'Desigualdade e Pobreza no Brasil', IPEA, Rio de Janeiro, pp. 81-108.

IBGE (2004), Pesquisa de orçamentos familiares 2002-2003. CD-ROMMicrodados-Rio de Janeiro. 
IBGE (2010), Pesquisa de orçamentos familiares 2008-2009. CD-ROMMicrodados-Rio de Janeiro.

Lanjouw, P. (2005), 'Constructing a consumption aggregate for the purpose of welfare analysis: issues and recommendations concerning the pof 20022003 in Brazil', Development Economics Research Group, World Bank .

Philippi, S. T. (2002), Tabela de composição de alimentos: suporte para decisão nutricional, Brasília.

Quintães, V., Sousa, D., Duarte, C., Danielle, M., Santos, I. \& Assis, J. (2006), Análise do bem-estar a partir de um indicador de consumo agregado com base nas informações da pof 2002-2003, in 'Encontro Nacional de Estudos Populacionais, ABEP', Caxambu-MG. 18-22 de setembro.

Ravallion, M. (1998), Poverty lines in theory and in practice. LSMS Working Paper n. 133, Washington D.C., The World Bank.

Rocha, S. (1993), 'Renda e pobreza no Brasil', Revista Bras. Estudos Pop. 10(12), 99-106.

Rocha, S. (1996), Poverty studies in brazil - a review. Rio de Janeiro, IPEA, Texto para Discussão 439.

Rocha, S. (2000), Estimação de linhas de indigência e de pobreza: opções metodológicas no Brasil, in R. Henriques, ed., 'Desigualdade e Pobreza no Brasil', IPEA, Rio de Janeiro, pp. 685-718.

Rocha, S. (2006), Pobreza no Brasil: afinal de que se trata?, 3 edn, FGV.

\section{Apêndice A}


Tabela A.1: Coeficientes da regressão de despesa com alimentos contra características socioeconômicas dos domicílios para os três modelos de imputação, POF 2008-2009

\begin{tabular}{|c|c|c|c|c|c|c|}
\hline \multirow{2}{*}{ Variáveis } & \multicolumn{2}{|c|}{ Modelo 1: Gasto Zero em Alimentos } & \multicolumn{2}{|c|}{ Modelo 2: Strict Cutoffs } & \multicolumn{2}{|c|}{ Modelo 3: Gradual Cutoffs } \\
\hline & Coef. & p-valor & Coef. & p-valor & Coef. & p-valor \\
\hline $\begin{array}{l}\text { Logaritmo da Despesa não } \\
\text { Alimentar Per Capita }\end{array}$ & 0,55000 & 0,00000 & 0,57000 & 0,00000 & 0,61000 & 0,00000 \\
\hline Norte & 0,16000 & 0,00000 & 0,14000 & 0,00000 & 0,14000 & 0,00000 \\
\hline Sul & $-0,09000$ & 0,00000 & 0,04000 & 0,03900 & 0,05000 & 0,01000 \\
\hline Sudeste & $-0,07000$ & 0,00000 & $-0,00400$ & 0,76200 & $-0,00700$ & 0,67500 \\
\hline Centro-Oeste & $-0,24000$ & 0,00000 & $-0,11000$ & 0,00000 & $-0,12000$ & 0,00000 \\
\hline Rural & 0,06000 & 0,00000 & 0,10000 & 0,00000 & 0,12000 & 0,00000 \\
\hline Idade & $-0,00040$ & 0,42000 & 0,00030 & 0,52300 & $-0,00008$ & 0,88700 \\
\hline Total de Pessoas & $-0,04800$ & 0,00000 & $-0,06000$ & 0,00000 & $-0,05000$ & 0,00000 \\
\hline Sexo & 0,07000 & 0,00000 & 0,10000 & 0,00000 & 0,11000 & 0,00000 \\
\hline Branca & 0,01000 & 0,45600 & 0,03000 & 0,03500 & 0,03000 & 0,07600 \\
\hline Preta & $-0,08000$ & 0,00000 & $-0,10000$ & 0,00000 & $-0,10000$ & 0,00000 \\
\hline Amarela & 0,04000 & 0,65200 & 0,15000 & 0,03400 & 0,14000 & 0,07300 \\
\hline Indígena & 0,08000 & 0,23000 & 0,00800 & 0,90500 & 0,01000 & 0,87800 \\
\hline $\begin{array}{l}\text { Proporção de Crianças e } \\
\text { Adolescentes no Domicílio }\end{array}$ & $-0,15000$ & 0,00000 & $-0,16000$ & 0,00000 & $-0,16000$ & 0,00000 \\
\hline Proporção de Idosos no Domicílio & 0,01000 & 0,60000 & 0,10000 & 0,00000 & 0,12000 & 0,00000 \\
\hline Empregado & 0,10000 & 0,00000 & 0,09000 & 0,00000 & 0,10000 & 0,00000 \\
\hline Empregado Temporário Rural & 0,14000 & 0,00100 & 0,10000 & 0,01100 & 0,11000 & 0,00900 \\
\hline Empregador & 0,17000 & 0,00000 & 0,16000 & 0,00000 & 0,19000 & 0,00000 \\
\hline Trabalhador por Conta Própria & 0,11000 & 0,00000 & 0,09000 & 0,00000 & 0,10000 & 0,00000 \\
\hline Trabalhador para Consumo Próprio & 0,17000 & 0,00000 & 0,11000 & 0,00300 & 0,14000 & 0,00100 \\
\hline Chefe Remunerado & $-0,89000$ & 0,00000 & $-0,91000$ & 0,01400 & $-0,97000$ & 0,01500 \\
\hline Escolaridade do Chefe (4-8 Anos) & $-0,01000$ & 0,37900 & 0,01000 & 0,41200 & 0,01200 & 0,49700 \\
\hline Escolaridade do Chefe (8-12 Anos) & $-0,02000$ & 0,24900 & 0,03000 & 0,05200 & 0,04400 & 0,02500 \\
\hline Escolaridade do Chefe (12 ou mais) & 0,09000 & 0,00000 & 0,12000 & 0,00000 & 0,12000 & 0,00000 \\
\hline Constante & 2,40000 & 0,00000 & 2,32000 & 0,00000 & 2,25000 & 0,00000 \\
\hline N Observações & \multicolumn{2}{|c|}{51726} & \multicolumn{2}{|c|}{38118} & \multicolumn{2}{|c|}{38118} \\
\hline $\mathrm{R}^{2}$ & \multicolumn{2}{|c|}{0,31} & \multicolumn{2}{|c|}{0,44} & \multicolumn{2}{|c|}{0,44} \\
\hline
\end{tabular}


Tabela A.2: Despesa com alimentação média per capita para os modelos de imputação por macro região, POF 2008-2009

\begin{tabular}{lcccc}
\hline \multirow{2}{*}{ Regiões } & Amostra Sem Imputação & \multicolumn{3}{c}{ Amostra com Imputação } \\
\cline { 3 - 5 } & $\begin{array}{l}\text { Modelo 1: Gasto Zero } \\
\text { em Alimentos }\end{array}$ & $\begin{array}{c}\text { Modelo 2: } \\
\text { Strict Cutoffs }\end{array}$ & $\begin{array}{c}\text { Modelo 3: } \\
\text { Gradual Cutoffs }\end{array}$ \\
\hline Norte & 129,1545 & 131,6940 & 138,9693 & 145,0771 \\
Nordeste & 108,0344 & 110,2173 & 116,9014 & 120,7692 \\
Sul & 158,3037 & 163,0333 & 183,5886 & 197,9216 \\
Sudeste & 160,7080 & 165,4155 & 181,5397 & 192,6651 \\
Centro-Oeste & 127,8624 & 135,0058 & 149,8432 & 157,3493 \\
Rural & 105,7786 & 110,7280 & 119,8603 & 125,8825 \\
Urbano & 148,5757 & 152,4990 & 166,9631 & 176,6342 \\
Brasil & 141,8580 & 145,9423 & 159,5695 & 168,6678 \\
\hline Fonte: Dados & & &
\end{tabular}


Tabela A.3: Valores dos fluxos médios de serviços mensais para os bens duráveis incluídos no inventário para a POF 2002-2003 e POF 2008-2009

\begin{tabular}{|c|c|c|}
\hline Bens & $\begin{array}{c}\text { POF 2002-2003 } \\
\text { Valor do Fluxo de Serviços }\end{array}$ & $\begin{array}{c}\text { POF 2008-2009 } \\
\text { Valor do Fluxo de Serviços }\end{array}$ \\
\hline Fogão & 20,41 & 29,78 \\
\hline Freezer & 8,28 & 10,16 \\
\hline Geladeira & 38,00 & 63,14 \\
\hline Chuveiro Elétrico & - & 3,22 \\
\hline Liquidificador & 4,19 & 6,11 \\
\hline Processador de Alimentos & - & 2,06 \\
\hline Grill & - & 1,72 \\
\hline Aspirador de Pó & 2,25 & 3,06 \\
\hline Forno Elétrico & - & 3,87 \\
\hline Ferro Elétrico & 3,22 & 4,25 \\
\hline Máquina de Lavar Roupas & 25,28 & 32,43 \\
\hline Televisão em Cores & 41,35 & 51,97 \\
\hline Televisão em Preto e Branco & 0,29 & 0,09 \\
\hline Equipamento de Som & 22,58 & 19,71 \\
\hline Rádio & 2,39 & 3,44 \\
\hline Ar-condicionado/Climatizador/Aquecedor de $\mathrm{Ar}$ & 7,10 & 9,81 \\
\hline Ventilador e/ou Circulador de Ar & 4,05 & 5,76 \\
\hline Máquina de Costura & 3,14 & 5,53 \\
\hline Automóvel & 144,41 & 440,45 \\
\hline Bicicleta & 5,75 & 7,94 \\
\hline Motocicleta & 13,12 & 52,00 \\
\hline Microcomputador/Notebook/Laptop/Computador Portátil & 34,96 & 59,97 \\
\hline Purificador de Água & 1,98 & 1,86 \\
\hline Forno de Micro-ondas & 9,43 & 10,28 \\
\hline Antena Parabólica & 6,85 & 8,00 \\
\hline Aparelho de DVD & 3,93 & 13,81 \\
\hline Máquina de Secar Roupas & 1,65 & 1,66 \\
\hline Batedeira de Bolo & 2,86 & 3,61 \\
\hline Secador de Cabelos & 1,67 & 3,11 \\
\hline Máquina de Lavar Louças & 1,84 & 1,55 \\
\hline
\end{tabular}


Tabela A.4: Distribuição do total de gastos per capita das famílias no percentis 20 e 40 para o Brasil, POF 2002-2003 e POF 2008-2009

\begin{tabular}{lcccc}
\hline Variável & Percentil & POF 2002-2003 & $\begin{array}{c}\text { POF 2002-2003 } \\
\text { (Inflacionado para } \\
\text { jan de 2009) }\end{array}$ & POF 2008-2009 \\
\hline Despesa Total Per Capita (R\$) & 20 & 97,53 & 138,17 & 162,54 \\
& 40 & 163,87 & 232,15 & 267,77 \\
\hline
\end{tabular}

Fonte: Dados da pesquisa. 
Tabela A.5: Composição da cesta de necessidades básicas da POF 2008-2009

\begin{tabular}{|c|c|c|c|c|c|c|}
\hline Produto & $\begin{array}{l}\text { Caloria } \\
\text { por } \\
\text { kg } \\
\text { (a) }\end{array}$ & $\begin{array}{c}\text { Quantidade Média } \\
\text { em kg per Capita } \\
\text { por Dia (Percentil 20 a 40) } \\
\text { (b) }\end{array}$ & $\begin{array}{l}\text { Total Médio de } \\
\text { Caloria per Capita } \\
\text { por Dia }\left(a^{*} b\right) \\
(c)\end{array}$ & $\begin{array}{c}\text { Quantidade Média } \\
\text { em kg Convertida } \\
\text { per Capita por Dia }\left(b^{*} 0,56\right) \\
(d)\end{array}$ & $\begin{array}{c}\text { Total de Calorias } \\
\text { Convertido per } \\
\text { Capita por Dia }\left(\mathrm{a}^{*} \mathrm{~d}\right) \\
(\mathrm{e})\end{array}$ & Preço \\
\hline Arroz & 1273,3 & 0,1974304 & 251,3881280 & 0,112001476 & 142,611479600 & 2,0015330 \\
\hline Feijão & 791,4 & 0,0855037 & 67,6676282 & 0,048505907 & 38,387574800 & 3,2665570 \\
\hline Refrigerante & 380,0 & 0,1192863 & 45,3287940 & 0,067670641 & 25,714843520 & 1,3998340 \\
\hline Tomate & 180,0 & 0,0412137 & 7,4184660 & 0,023380367 & 4,208466080 & 2,3623540 \\
\hline Cebola & 295,0 & 0,0322559 & 9,5154905 & 0,018298643 & 5,398099699 & 1,8395170 \\
\hline Batata Inglesa & 1290,0 & 0,0495538 & 63,9244020 & 0,028111673 & 36,264057560 & 1,7076010 \\
\hline Banana & 1000,0 & 0,0716953 & 71,6953000 & 0,040672457 & 40,672456910 & 2,5490800 \\
\hline Farinha de Mandioca & 3630,0 & 0,1247309 & 452,7731670 & 0,070759341 & 256,856406500 & 1,6283880 \\
\hline Farinha de Trigo & 3600,0 & 0,0788716 & 283,9377600 & 0,044743543 & 161,076755500 & 2,0907990 \\
\hline Fubá de Milho & 3530,0 & 0,0770298 & 271,9151940 & 0,043698697 & 154,256401900 & 1,7159360 \\
\hline Macarrão & 3020,0 & 0,0378459 & 114,2946180 & 0,021469828 & 64,838879610 & 3,3731880 \\
\hline Pão Francês & 3000,0 & 0,0497154 & 149,1462000 & 0,028203348 & 84,610042680 & 4,1271640 \\
\hline Biscoito & 4721,7 & 0,0274348 & 129,5388950 & 0,015563652 & 73,486897070 & 6,1512870 \\
\hline Carne de Boi de Primeira & 2374,0 & 0,0604920 & 143,6080080 & 0,034316870 & 81,468248510 & 10,0808800 \\
\hline Carne de Boi de Segunda & 2662,8 & 0,0738478 & 196,6419220 & 0,041893562 & 111,554175700 & 7,1114430 \\
\hline Carne Suína & 3505,0 & 0,0545270 & 191,1171350 & 0,030932949 & 108,419986200 & 7,0818690 \\
\hline Frango & 2025,4 & 0,0910555 & 184,4238100 & 0,051655421 & 104,622889500 & 4,7119170 \\
\hline Ovo de Galinha & 1460,0 & 0,0284110 & 41,4800600 & 0,016117447 & 23,531472120 & 5,9811450 \\
\hline Leite & 502,6 & 0,1855898 & 93,2848571 & 0,105284351 & 52,920126280 & 1,6266680 \\
\hline Queijo & 2894,0 & 0,0203620 & 58,9276280 & 0,011551281 & 33,429407650 & 12,1513400 \\
\hline Açúcar & 3870,0 & 0,1238003 & 479,1071610 & 0,070231415 & 271,795576000 & 1,1185900 \\
\hline Chocolate em Pó & 4010,0 & 0,0140509 & 56,3441090 & 0,007971019 & 31,963787660 & 7,7212860 \\
\hline Óleo de Soja & 8840,0 & 0,0574135 & 507,5353400 & 0,032570449 & 287,922768200 & 3,1158660 \\
\hline Margarina & 6265,0 & 0,0167118 & 104,6994270 & 0,009480537 & 59,395566140 & 5,3483180 \\
\hline Embutido & 2269,0 & 0,0330467 & 74,9829623 & 0,018747261 & 42,537534580 & 6,8159620 \\
\hline Café & 90,0 & 0,0403040 & 3,6273600 & 0,022864298 & 2,057786819 & 8,7817840 \\
\hline Total & \multicolumn{4}{|c|}{4054,32382} & \multicolumn{2}{|c|}{2300,001687} \\
\hline
\end{tabular}


